\title{
Efeito de diferentes tratamentos de superfície na resistência de união de um cimento resinoso à zircônia
}

\section{Polliana Mendes Candia Scaffa}

Dissertação apresentada à Faculdade de Odontologia de Bauru da Universidade de São Paulo para obtenção do título de mestre em Odontologia. 
UNIVERSIDADE DE SÃO PAULO

Faculdade de Odontologia de Bauru

\section{Efeito de diferentes tratamentos de superficie na resistência de união de um cimento resinoso à zircônia}

\section{Polliana Mendes Candia Scaffa}

Dissertação apresentada à Faculdade de Odontologia de Bauru da Universidade de São Paulo para obtenção do título de mestre em Odontologia.

Área de concentração: Dentística

Orientador: Prof. Dr. Rafael Francisco Lia Mondelli Co-orientador: Prof. Dr. Carlos Eduardo Francischone 
Scaffa, Polliana Mendes Candia

Efeitos de diferentes tratamentos de superfície na resistência de união de um cimento resinoso à zircônia/ Polliana Mendes Candia Scaffa --Bauru, 2009.

95p.: il.; $31 \mathrm{~cm}$.

Dissertação (Mestrado) - Faculdade de Odontologia de Bauru, da Universidade de São Paulo.

Orientador: Prof. Dr. Rafael Francisco Lia Mondelli

Autorizo, exclusivamente para fins acadêmicos e científicos, a reprodução total ou parcial desta dissertação/tese, por processos fotocopiadores e/ou meios eletrônicos.

Assinatura do autor:

Data: 


\section{Dados Curriculares}

\section{Polliana Mendes Candia Scaffa}

02 de agosto de 1983 Nascimento

Naturalidade $\quad$ Campo Grande - MS

Filiação

Paulo José Candia Scaffa

Rocilma Mendes Candia Scaffa

2001-2004

Curso de Graduação em Odontologia pela Faculdade de Odontologia da Universidade Federal do Mato Grosso do Sul - UFMS

2005-2007

Curso de Especialização em Dentística pela UFMS

$2007-2009$

Curso de Pós-Graduação em Dentística, em nível de Mestrado, pela Faculdade de Odontologia de Bauru da Universidade de São Paulo - FOB/USP

Associações

Grupo Brasileiro de Professores de Dentística Sociedade Brasileira de Pesquisa Odontológica International Association for Dental Research 
"A mente que se abre a uma nova idéia jamais voltará ao seu tamanho original."

Albert Einstein

- iv - 


\section{D edicatória}

Dedico este trabalho,

À Deus, pelas oportunidades a mim oferecidas, por ter me guiado sabiamente a contornar todos os obstáculos e iluminado a minha trajetóría, colocando pessoas maravithosas no meu caminho.

Aos meus pais, Paulo José e Rocíma, vocês são meus exemplos de dedicação e superação. O apoío e a compreensão de vocês sempre foram fundamentais na minha caminhada. Obrígada por todo amor, carinho e confiança que sempre depositaram em mim. Pelo incentivo nos momentos de incerteza e por todas as alegrias que passamos juntos, enfim foram 25 anos aprendendo valores fundamentais para esta conquista.

Aos meus irmãos, Paolla e Nícolla, obrigada pela amizade e companhia, por todas as rísadas e até mesmo brigas. Pelas conversas, viagens, pelos chopps, conselhos, pelo apoio e incentivo nos momentos dificeis. Enfím, por todos os momentos em que estivemos juntos. $\mathcal{E}$ sempre muito bom estar ao lado de vocês. 
ม̀ minha tía, Denise, uma pessoa do bem, dedicada e atenciosa. Obrígada por estar sempre ao meu lado, e não deixar de medir esforços para que eu pudesse buscar os meus sonhos. Sou muito grata por tê-la em minha vida.

Ao meu tio Sérgio, e minha avó, María Alzira, que sempre me apoiaram e acreditaram nos meus sonhos, vibrando comigo a cada conquista. Muito obrigado por todos os mimos e carinhos.

À matriarca da familia, Bisa, um exemplo de alto astral e vontade de viver, me ensina como é bom envelhecer com alegría. $\mathcal{A}$ minha bisavó, Elzira (in memoriam), que partíu antes que este momento chegasse, mas deixou uma enorme lição de vida.

Ao meu namorado, Gustavo, que sempre me deu força para correr atrás dos meus sonhos, que compreendeu a minha ausêncía e me ofereceu o melhor através de gestos e palavras de amor $e$ apoio. $\mathcal{E}$ sempre bom estar ao seu lado.

"As palavras de amizade e conforto podem ser curtas e sucintas, mas o seu eco é infindável." Madre Teresa de Calcutá 


\section{A gradecimentos E speciais}

\section{A os professores,}

Prof. Dr. Carlos Eduardo Francischone

Com sua tranqüilidade, bom humor e confecimento, guiou meus passos nos últimos dois anos. Obrigada pela confiança em mim depositada e pela disponibilidade em me orientar neste trabalho, pois mesmo com seus compromissos importantes nunca deixou de me receber. Agradeço pelo incentivo no crescimento da minha vida acadêmica e por ter-me orientado de forma sábia, respeitando minhas opinióes e, ao mesmo tempo, guiando-me pelo melhor caminho. Obrigada pela oportunidade de pesquisarmos e publicarmos juntos e, acima de tudo, obrigada por não poupar esforços em me ajudar.

Aos Professores do Departamento de Dentística,

Prof. Dr. José Mondelli, Prof. Dr. José Carlos Pereira, Prof. Dr. Aquira Ishikiriama, Prof. Dr. Eduardo Batista Franco, Prof. Dr. Sergio Kiyoshi Ishikiriama, Profa. Maria Tereza Atta, Profa. Dr. Linda Wang, pelo convivio amistoso, pela amizade, pelos ensinamentos e oportunidades oferecidas durante o programa de mestrado. 
Aos Professores do Departamento de Materiais Dentáríos, Prof. Dr. Paulo Amarante de Araujo, Prof. Dr. César Antunes de Freitas e Prof. Dr. Paulo Afonso Sílveira Francisconi, pela amizade, dedicação, incentivo e forma carinhosa com que me acolheram em seu departamento.

Aos meus professores da graduação, da Faculdade de Odontologia "Albino Coimbra Filho" - UFMS, que me proporcionaram todo embasamento científico para iniciar essa jornada.

"Não se pode ensinar alguma coisa a alguém, pode-se apenas auxiliar a descobrir por si mesmo." Galileu Galilei 


\section{A os queridos amigos,}

Às amigas e professoras Teresa e Linda, pelo modo afetuoso com que sempre me trataram. As conversar agradáveis, os consethos, nossas reunióes, enfim aos momentos de alegria que tivemos nesse periodo de convivêncía.

$\mathcal{A}$ amiga e professora, Margareth Coutinho, ... que acreditou em mim, incentivou e procurou me ajudar em todos os sentidos. Sempre muito dedicada, atenciosa e preocupa em contribuir com o meu crescimento, tenho você um exemplo de professora e profissional. Obrigada pelos ensinamentos, pelos conselhos, pela ajuda. Suas palavras e gestos sempre me deram forças para seguir buscando os meus sonhos.

A família Francísconi, pelo carínho que sempre demonstraram por mim. Muito obrigada, vocês são pessoas formidáveis, pelas quais tenho um profundo carinho. Acotheramme e nunca mediram esforços em ajudar. Foi muito bom conviver com vocês esses 2 anos.

À minha turma de Pós-Graduação, Eugênio, Ivonne, Juan, Karín, Flávía, Leonardo, Leslie, Lulu, Lu, Lourdes, Paula, Rícardo, pela convivência e companheirismo. Pelas experiências que compartilhamos, sofremos juntos, sorrimos juntos e vencemos. 
A minha familia do mestrado...

Lulu, Lu, Magrela (Flávía), Paulinha, minha equipe de apoio 24 horas. Parceiras em todos os momentos... para montar seminários, escrever artigos, atender pacientes, emprestar o carro, ficar de motorista, ir ao supermercado, fazer jantares e mais jantares, conversar, fofocar, dar conselhos, dividir sonhos $e$ medos. Enfím, formamos uma família aqui em Bauru, daquela que podemos contar nos momentos de alegria e nos de tristeza. Vocês sabem e valorizam o significado da palavra amizade. Muito obrigada pelos diversos momentos em que estivemos juntas e por tudo que vocês fizeram por mim. Karin, aos poucos revelou-se amiga e companheira pra todas as horas. Leslie, Ivonne, e Paulinha, além de companheiras de turma, foram minhas parceiras para festas, bares, churrascos. Sempre muito animadas e divertidas, vocês foram essenciais. Lourdes, exemplo de garra e determinação, apesar de quietinha, esteve sempre presente.

Aos "agregados" da turma, Cintinha, Gustavo e Dríca, Leandro, Marcela, Wagner e Zezo, obrigada pelo convivio, amizade, companheirismo, pelas conversas, reunióes gastronômicas e pelas alegrias que compartilhamos.

Ao Juan Rommel, Renato e Aninha, pela orientação e ajuda na execução do meu experímento, pelas idéias e sugestões e pelas longas conversas nas clínicas da graduação. 
Aos amigos da graduação, em especial as meninas da $\chi_{\mathcal{L}} \mathcal{V}$, mais que simples orientadas, tornaram-se amigas. Galerinha companheira de conversas, reuniões e festinhas. Vocês são especiais.

Aos velhos amigos de Campo Grande, que apesar de seguirmos camínhos tão diferentes, mesmo à distâncía, não deixaram de fazer parte da minha vida, as conversas por $\mathcal{M S \mathcal { N }}$, nossas reunióes gastronômicas, nossas rodas de tereré, os conselhos, as formaturas, festas, casamentos, enfim, sempre que estamos juntos os momentos são de alegría e descontração.

As amigas dentistas, Ana Camila, Anadir, Ariene, Suellen, Vivian Stuhrk, Vivian Rosa, Juzinha, sempre me apoiaram e ajudaram no que foi preciso, foram muitas palavras de conforto, favores, reunióes, discussão de casos, enfím, vocês dividiram suas experiências e contríbuíram para o meu desenvolvimento.

"A amizade desenvolve a felicidade e reduz o sofrimento, duplicando a nossa alegria e dividindo a nossa dor." Joseph Addison 


\section{A os funcionários,}

Aos funcionários do Departamento de Dentística e da PósGraduação, Rita, Ângela, $\mathcal{N}$ elson, Maria, Mauro, Junior, Zuleica, Dito, Cleuza, Hebe, pela dedicação, colaboração e ajuda, por sempre me atenderem de forma solicita e alegre, esclarecendo as minhas duvidas e auxiliando com as questões burocráticas, tornando tudo muito maís fácíl.

Aos funcionários e amigos do Departamento de Materiais Dentários, Sandrinha, Lô e Alcides, por não pouparem esforços para ajudar. Obrigada por sempre receberem os afunos de braços abertos e com um bom cafezinho, por contribuírem para o bom andamento das nossas pesquisas. Alcides você foi fundamental.

Aos integrantes do CIP-I (Centro Integrado de Pesquisa I), por tratarem os alunos com carinho, compreensão e respeito. 


\section{A gradecimentos I nstitucionais}

À Prof ${ }^{\mathrm{a}}$. Dr ${ }^{\mathrm{a}}$. Suely Vilela, digníssima reitora da Universidade de São Paulo;

À Prof ${ }^{a}$. Dra . Maria Fidela de Lima Navarro, digníssima Secretária Geral da Universidade de São Paulo;

Ao Prof. Dr. Luiz Fernando Pegoraro, digníssimo Diretor da Faculdade de Odontologia de Bauru da Universidade de São Paulo;

Ao Prof. Dr. José Roberto Magalhães Bastos, digníssimo Prefeito do Campus da Faculdade de Odontologia de Bauru da Universidade de São Paulo;

À Prof ${ }^{\mathrm{a}}$. Dr ${ }^{\mathrm{a}}$. Maria Aparecida de Andrade Moreira Machado, digníssima Presidente da Pós-Graduação da Faculdade de Odontologia de Bauru da Universidade de São Paulo;

À equipe do Laboratório Ero Prótese, sempre muito atenciosa, disponibilizou o aparelho Rocatec para a realização dessa pesquisa.

Ao Conselho Nacional de Desenvolvimento Científico e Tecnológico (CNPq), órgão de fomento deste trabalho.

... vocês fazem parte dessa vitóría, a todos, o meu reconhecimento e agradecimento!!! 


\section{RESUMO}




\section{Resumo}

As cerâmicas à base de zircônia (Y-TZP) apresentam propriedades mecânicas superiores às das demais cerâmicas odontológicas. Entretanto, o aumento do conteúdo cristalino modificou suas características de adesão a cimentos resinosos, tornando necessário o desenvolvimento de métodos mais efetivos de união a estes materiais. Este trabalho in vitro pretende, portanto, avaliar a influência de diferentes tratamentos de superfície e de diferentes agentes de união na resistência ao cisalhamento entre uma zircônia estabilizada por ítrio e um agente cimentante autoadesivo (RelyX U100 ${ }^{\circledR} / 3 \mathrm{M}$ ESPE). Para tal, cilindros de PROCERA ${ }^{\circledR}$ Allzircon receberam como tratamento de superfície jateamento com óxido de alumínio $\left(\mathrm{Al}_{2} \mathrm{O}_{3}\right.$ $50 \mathrm{~m}$ ) ou jateamento com o sistema Rocatec. Sobre a superfície tratada dos cilindros foram aplicados, de acordo com os diferentes grupos experimentais, o sistema adesivo Clearfil SE Bond ${ }^{\circledR}$ (Kuraray Co.), e os primers Metal Zirconia Primer (Ivoclar Vivadent) e Alloy Primer (Kuraray Co.) e, finalmente, o cimento resinoso adotado. Cada espécime foi, então, submetido ao teste de cisalhamento $(0,05$ $\mathrm{mm} / \mathrm{min}$ ), por meio da ação de uma alça de fio ortodôntico passando o mais próximo possível da interface adesiva. A análise de variância a um critérios (ANOVA) e o teste de Tukey $(p<0,05)$ mostraram que a realização do tratamento de superfície aumentou os valores de resistência de união entre a cerâmica e o cimento resinoso. O jateamento com o sistema Rocatec $(15,33 \mathrm{MPa})$ apresentou valores significantemente maiores que o jateamento com $\mathrm{Al}_{2} \mathrm{O}_{3}(11,93 \mathrm{MPa})$. A aplicação dos agentes de união resultou em uma maior resistência adesiva, sendo que o sistema adesivo Clearfill SE Bond (17,07 MPa) teve um comportamento estatisticamente superior aos demais materiais. Entre os primers, o Metal Zircônia Primer (11,26 $\mathrm{MPa}$ ) apresentou maior valor de resistência de união que o Alloy Primer (10,01 $\mathrm{MPa}$ ). Portanto, a associação de um tratamento superficial com um agente de união é valida, já que promoveu os maiores valores de resistência adesiva.

Unitermos: Tratamentos de superfície. Resistência de união. Zircônia (Y-TZP). Jateamento com $\mathrm{Al}_{2} \mathrm{O}_{3}$. Revestimento com sílica. MDP. Cimento resinoso. 


\section{ABSTRACT}

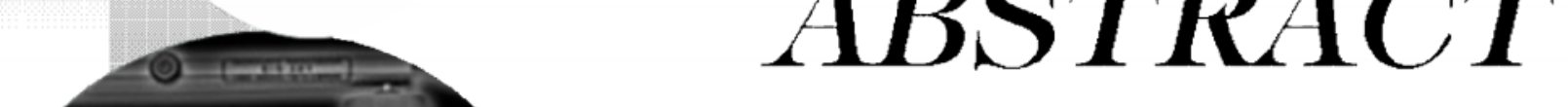




\section{Abstract}

Yttrium-stabilized tetragonal zircon polycrystal (Y-TZP) ceramics show better mechanical properties than other dental ceramics. However, the high crystalline content modified their adhesiveness to resin cements, making it extremely necessary to develop a more effective adhesive strategy between them. This in vitro study intends to evaluate the influence of different surface treatments and different bond agents on the shear bond strength between a Y-TZP and self-adhesive resin cement. PROCERA $^{\circledR}$ Allzircon cylinders (3.5 $\mathrm{mm}$ in diameter) received a surface airborne abrasion treatment with $50 \mathrm{~m}$ aluminum-oxide $\left(\mathrm{Al}_{2} \mathrm{O}_{3}\right)$ particles or with the Rocatec system. According to the experimental groups, the adhesive system Clearfil SE Bond $^{\circledR}$ (Kuraray Co.), and the primers Metal Zirconia Primer (Ivoclar Vivadent) and Alloy Primer (Kuraray Co.) were applied on the treated surface of the cylinders, before the application of the adopted resin cement (RelyX U100 ${ }^{\circledR} / 3 \mathrm{M}$ ESPE). Each specimen was submitted to the shear bond strength test $(0.5 \mathrm{~mm} / \mathrm{min})$, by the action of an orthodontic stainless steel ligature wire $(0.5 \mathrm{~mm}$ in diameter) loop, wrapped around the resin cement, as close as possible to the adhesive interface. One wayANOVA and Tukey's post hoc tests $(p<0.05)$ revealed that surface treatment increased bond strength between the ceramic and the resin cement. Silica coating with the Rocatec system (15.33 MPa) showed significantly higher values than airborne abrasion with $\mathrm{Al}_{2} \mathrm{O}_{3}$ (11.93 MPa). Application of all bond agents improved shear bond strength: adhesive system Clearfil SE Bond (17.07 MPa) showed better performance than the other evaluated materials, and Metal Zirconia Primer (11.26 $\mathrm{MPa}$ ) showed higher bond strength values than Alloy Primer (10.01 MPa). Therefore, the association of a surface treatment with a bond agent is suitable, once it resulted in higher values of adhesive strength.

Keywords: Surface treatments. Bond strength. Zirconia (Y-TZP). Airborne abrasion with $\mathrm{Al}_{2} \mathrm{O}_{3}$. Silica coating. Resin cement. 


\section{SUMÁRIO}

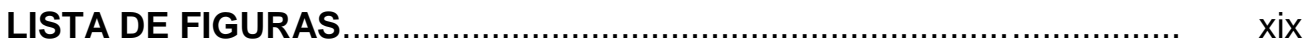

LISTA DE TABELAS .................................................................... $\mathrm{xX}$

LISTA DE ABREVIATURAS .................................................. $\quad$ xxi

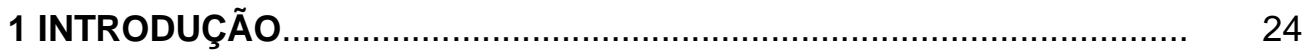

2 REVISÃO DE LITERATURA ........................................................ 30

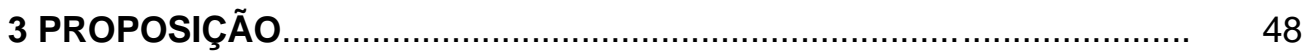

4 MATERIAL E MÉTODOS ......................................................... 50

4.1 MATERIAL UTILIZADO ........................................................... 53

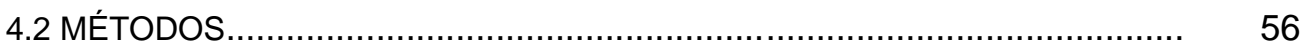

4.2.1 Delineamento Experimental...................................................... 56

4.2.2 Dispositivos para confecção dos espécimes.................................. 56

4.2.3 Procedimentos Prévios............................................................... 5

4.2.4 Preparo dos Espécimes........................................................ 58

4.2.5 Teste de Resistência ao Cisalhamento........................................ 59

4.3 CONVERSÃO DE VALORES................................................................. 60

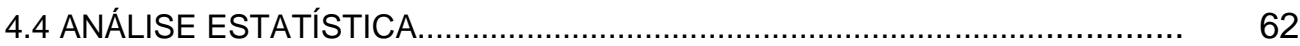

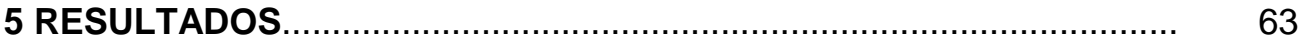

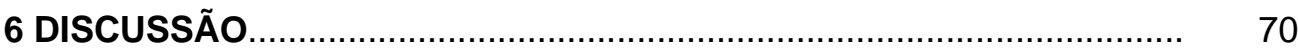

6.1 Da justificativa e proposição............................................................ 71

6.2 Da metodologia........................................................................ $\quad 74$

6.3 Dos resultados............................................................................. $\quad 79$

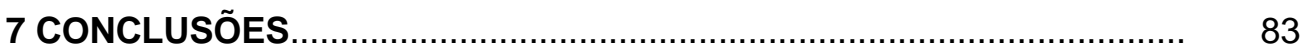

8 REFERÊNCIAS.BIBLIOGRÁFICAS............................................ 85

ANEXOS 


\section{LISTA DE FIGURAS}

Figura 1 Cimento resinoso utilizado no estudo RelyX U100/3M ESPE 55

Figura 2 Sistema adesivo Clearfill SE Bond/Kuraray 55

Figura 3A Silano RelyX Ceramic Primer/3M ESPE 55

Figura 3B Primer Alloy Primer/Kuraray 55

Figura 3C Primer Metal Zircônia Primer/lvoclar 55

Figura 4A Aparelho utilizado no jateamento com óxido de alumínio 55

Figura 4B Aparelho do sistema Rocatec 55

Figura 5 Dispositivos: (A)- matriz de teflon dividida em duas partes; 57 (B)- infra-estrutura de zircônia; (C)- dispositivo metálico utilizado para manter os cilindros de porcelana e a matriz de teflon; (D)- matriz de teflon ajustada ao dispositivo metálico

Figura 6 Confecção espécimes: (A)- cilindro em posição; (B)- inserção 61 cimento com espátula Hu-Fridy; (C)- matriz preenchida; (D)espécime pronto

Figura 7 Matriz: (A)- Matriz de teflon; (B e C)- Espécime adaptado na 61 matriz para o ensaio mecânico.

Figura 8 Ensaio mecânico: (A)- maquina de ensaio universal EMIC; 62 (B)- espécime em posição, com a alça de fio ortodôntico posicionada para o tracionamento;(C)- momento de ruptura do espécime.

Gráfico 1 Valores médios, em MPa, dos diferentes sistemas de união 66

Gráfico 2 Valores médios, em $\mathrm{MPa}$, dos diferentes tratamentos 67 mecânicos realizados na superfície da zircônia

Gráfico 3 Valores médios, em MPa, dos diferentes grupos 68 experimentais

Gráfico 4 Valores médios, em MPa, mostrando a associação dos 69 diferentes tratamentos realizados 


\section{LISTA DE TABELAS}

Tabela 1 Apresentação da marca comercial, composição, fabricante e número do lote dos materiais utilizados na pesquisa.

Tabela 2 Distribuição dos diferentes grupos experimentais.

Tabela 3 Valores médios, em MPa, dos diferentes sistemas de união, 65 independente do tratamento mecânico realizado na superfície da infra-estrutura.

Tabela 4 Valores médios, em MPa, dos diferentes tratamentos 66 realizados na superfície da infra-estrutura, não levando em consideração os sistemas de união.

Tabela 5 Valores médios, em $\mathrm{MPa}$, na associação dos tratamentos avaliados, tratamento mecânico da superfície e sistema de união. 


\section{LISTA DE ABREVIATURAS E SÍMBOLOS}

\begin{tabular}{|c|c|}
\hline П & pi \\
\hline$r^{2}$ & raio \\
\hline$A$ & área \\
\hline+ & mais \\
\hline $\mathrm{F}$ & força \\
\hline$>$ & maior \\
\hline$<$ & menor \\
\hline $\mathrm{Al}_{2} \mathrm{O}_{3}$ & alumina \\
\hline $\mathrm{ZrO}_{2}$ & zircônia \\
\hline $\mathrm{N}$ & newton \\
\hline$\%$ & por cento \\
\hline S & segundos \\
\hline $\mathrm{mm}$ & milímetro \\
\hline $\mathrm{cm}$ & centímetro \\
\hline $\mathrm{nm}$ & nanômero \\
\hline $\mathrm{m}$ & micrômetro \\
\hline $\mathrm{GPa}$ & gigapascal \\
\hline $\mathrm{MPa}$ & megapascal \\
\hline$d p$ & desvio padrão \\
\hline $\mathrm{SiO}_{4}$ & óxido de silício \\
\hline $\mathrm{HfO}_{2}$ & óxido de háfnio \\
\hline$\stackrel{\circ}{C}$ & graus centígrados \\
\hline $\mathrm{KgF}$ & quilograma Força \\
\hline $\mathrm{km} / \mathrm{h}$ & quilômetro por hora \\
\hline
\end{tabular}


nível de significância

bar barg unidade de pressão

BisGMA

bisfenol glicidil metacrilato

$\mathrm{C}=\mathrm{C}$

ligações duplas de carbono

$\mathrm{Rc}$

resistência ao cisalhamento

CIV

cimento de ionômero de vidro

$\mathrm{mW} / \mathrm{cm}^{2}$

miliwatts por centímetro quadrado

4-META

4-metacriloiloxietil trimelitato anidro

ISO

International Standard Organization

Y-TZP

zircônia tetragonal estabilizada com ítrio

MDP

10-metacriloiloxidecil di-hidrogênio fosfato

CAD/CAM computer assisted design/computer assisted machining

6-VBATDT

6 (4-vinylbenzyl-n-propyl) amino-1,3,5-triazine-2,4-dithione 


\section{INTRODUÇÃO}
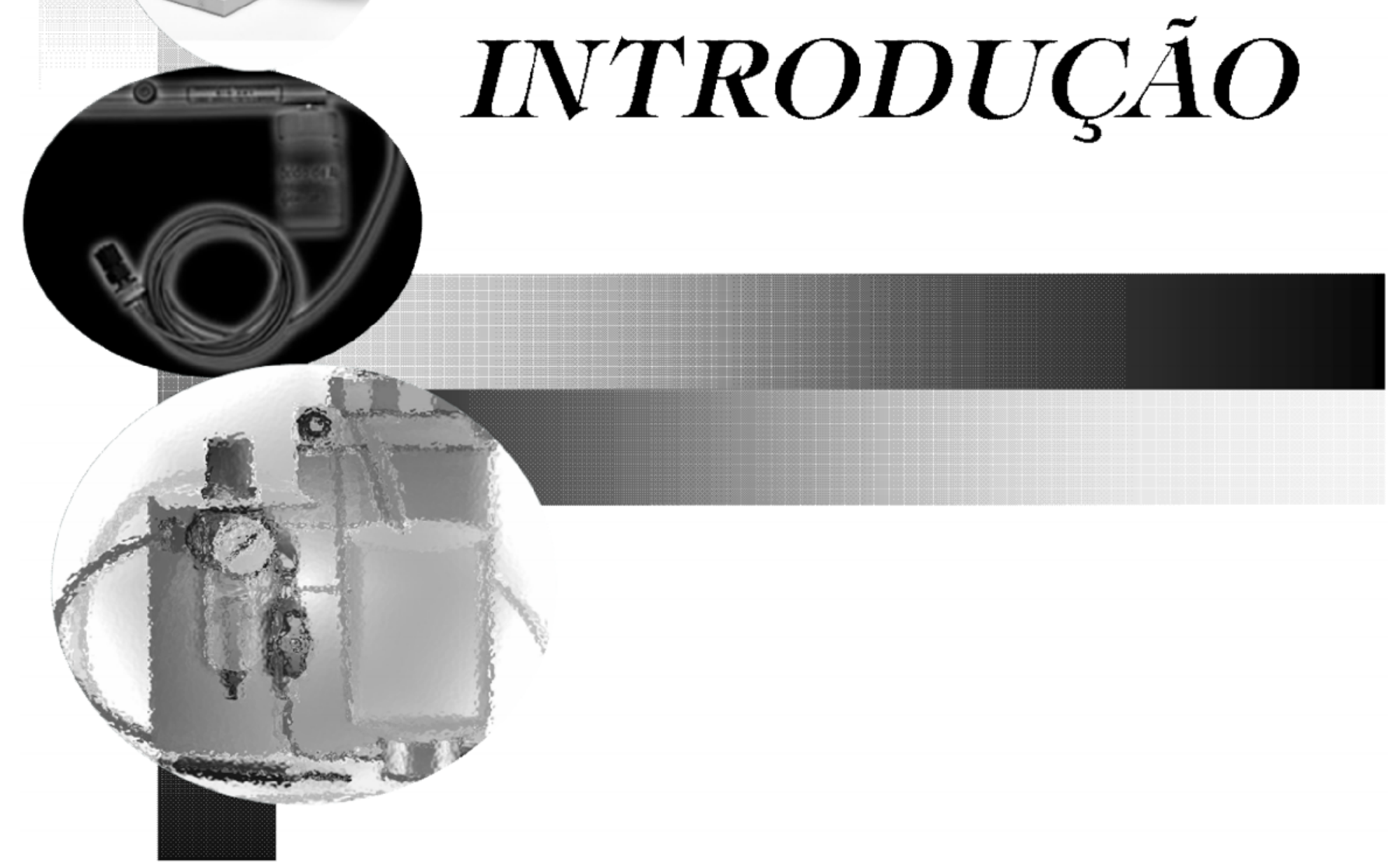


\section{INTRODUÇÃO}

A cerâmica destaca-se como uma alternativa que preenche os quesitos estéticos, biológicos, mecânicos e funcionais exigidos de um material restaurador, e tem sua indicação bem sedimentada na Odontologia (VAN NOORT, 2004).

Assim, o desenvolvimento de novos materiais, buscou eliminar a utilização de metal com a finalidade de melhorar as qualidades estéticas (McLEAN, 1991). Em uma primeira tentativa, McLean \& Hughs desenvolveram uma cerâmica com melhor resistência à flexão contendo $50 \%$ de óxido de alumina, proporcionando duas vezes mais resistência à fratura quando comparadas às cerâmicas feldspáticas convencionais (McLEAN; HUGHS, 1965).

A utilização de cerâmicas a base de zircônia $\left(\mathrm{ZrO}_{2}\right)$ de alta densidade vem sendo proposta, em função deste material apresentar uma excelente biocompatibilidade, alta dureza e resistência ao desgaste, além de resistência à flexão e alta tenacidade à fratura (DeAZA; CHEVALIER; FANTOZZI; SCHEHL; TORRECILLAS, 2002). A zircônia pura não pode ser utilizada na fabricação de peças sem a adição de estabilizantes. A zircônia estabilizada com ítrio (Y-TZP) se tornou uma alternativa popular à alumina como cerâmica estrutural, sendo também inerte em meio fisiológico, apresenta maior resistência à flexão, maior tenacidade à fratura e menor módulo de elasticidade. Além de suas propriedades mecânicas, a zircônia se torna esteticamente bastante interessante quando polida (PICONI; MACAURO, 1999).

A zircônia é utilizada na odontologia como agente opacificador, como reforço mecânico em porcelanas feldspáticas, material para fabricação de implantes dentários e núcleos intrarradiculares, subestruturas para prótese sobre implantes, para a confecção de "brackets" ortodônticos e como elemento principal na confecção de subestruturas de próteses odontológicas, quando submetida a grandes esforços mecânicos (PIWOWARCZYK; LAUER; SORENSEN, 2005). A zircônia possui uma série de vantagens sobre as outras cerâmicas, devido principalmente ao seu mecanismo de tenacificação por transformação, o qual pode conferir às peças propriedades mecânicas bastante 
interessantes, como elevada resistência mecânica e tenacidade (PICONI; MACCAURO, 1999; CHEVALIER; OLAGNON; FANTOZZI, 1999).

Atualmente, a zircônia parcialmente estabilizada com ítrio tornou-se uma opção viável para a confecção de infra-estruturas para restaurações totalmente cerâmicas, sendo que diversos sistemas Cercon (DeguDent), Lava All-Ceramic System (3M/ESPE) e Procera (Nobel Biocare) utilizam esse tipo de cerâmica, os quais empregam a tecnologia CAD/CAM (computer assisted design/computer assisted machining) para o seu processamento. Em 1993, foi desenvolvido o sistema Procera, por meio do qual os preparos dentais no modelo são registrados em computador e, via modem, são enviados para uma central na Suécia.

Paralelamente às cerâmicas, os agentes de cimentação também evoluíram, assim como, os adesivos dentais (FUSAYAMA; NAKAMURA; KUROSAKI; IWAKU, 1979; NAKABAYASHI; KOJIMA; MASUHARA, 1982). Os cimentos devem possuir algumas propriedades desejáveis, tais como favorável resistência a compressão e tração, suficiente espessura, biocompatibilidade, baixo esforço ao estresse e características de manipulação favoráveis (PIWOWARCZYK; LAUER; SORENSEN, 2005).

Apesar do domínio da técnica de cimentação para cerâmicas à base de sílica novos materiais que envolvem o emprego de alumina $\left(\mathrm{Al}_{2} \mathrm{O}_{3}\right)$ ou zircônia $\left(\mathrm{ZrO}_{2}\right)$ foram desenvolvidos. Estes apresentam alta concentração de conteúdo cristalino e elevadas propriedades mecânicas (PICONI; MACCAURO, 1999). Entretanto, o aumento do conteúdo cristalino resultou na redução ou eliminação da fase vítrea, o que modificou as características da união ao cimento resinoso. Considerando que o condicionamento com ácido fluorídrico dissolve a fase vítrea da cerâmica, quando esta fase é reduzida nenhum tipo de ácido produz retenção micromecânica suficiente para o procedimento de união (DERAND; DERAND, 2000; ÖZCAN; VALLITTU, 2003; LUTHARDT al., 2002).

Blatz, Sadan, Kern (2003) sugeriram que materiais cerâmicos de alta resistência como o dióxido de zircônio requerem técnicas adesivas alternativas para a obtenção de uma união satisfatória ao material resinoso. Estudos têm sugerido técnicas de cimentação específicas para cerâmicas Y-TZP. Estas técnicas incluem métodos de tratamento da superfície, a exemplo do 
jateamento com óxido de alumínio $\left(\mathrm{Al}_{2} \mathrm{O}_{3}\right)$ ou com partículas de sílica que podem variar de 30 a $110 \mu \mathrm{m}$, além do uso de materiais que promovam união química ao dióxido de zircônia (DERAND; MOLIN; KVAM, 2005; KERN \& WEGNER, 1998; KOSMAC; OBLAK; JEVNIKAR; FUNDUK; MARION, 1999; LUTHY; LOEFFEL; HAMMERLE, 2006; WOLFART; LEHMANN; WOLFART; KERN, 2007; YOSHIDA; YAMASHITA; ATSUTA, 2004).

O jateamento de superfícies com partículas de óxido de alumínio modificadas por sílica tem como objetivo produzir uma retenção micromecânica com a deposição de sílica, favorecendo a união química com o silano, fenômeno conhecido como silicatização. O sistema Cojet (3M-Espe) foi o primeiro a possibilitar o uso dessa tecnologia, possibilitando assim uma nova alternativa de tratamento da superfície para esse tipo de procedimento (ÖZCAN, 2002).

Atualmente, diferentes tipos de cimentos estão disponíveis no mercado. Estes incluem os cimentos de fosfato de zinco, cimento de ionômero de vidro convencional e modificado por resina, e os cimentos resinosos que podem ser convencionais ou os cimentos resinosos auto-adesivos. O cimento autoadesivo foi introduzido no mercado em 2002, como um novo subgrupo dos cimentos resinosos. A união dos cimentos resinosos convencionais, a base de BisGMA é considerada muito baixa para assegurar uma boa cimentação clínica (<3MPa) (DERAND; DERAND, 2000; KERN; WEGNER, 1998; LUTHY; LOEFFEL; HAMMERLE, 2006). Já o objetivo no desenvolvimento do cimento resinoso auto-adesivo (Rely X U100) foi combinar o fácil manuseamento e a ausência de pré-tratamento encontrado nos CIV com as propriedades mecânicas favoráveis, união satisfatória oferecida pelos cimentos resinosos.

Comparando-se o cimento RelyX U100 com outros 10 cimentos, incluindo cimentos resinosos, ionoméricos e de fosfato de zinco, Piwowarczyk, Lauer \& Sorensen, em 2005, através do ensaio de cisalhamento, após dois períodos de armazenagem, 30 minutos e 14 dias + termociclagem, verificaram que o cimento auto-adesivo RelyX U100 resultou nos melhores valores de resistência, em ambos os tempos e tratamentos superficiais.

Os cimentos resinosos a base de ácido fosfórico metacrilato (Panavia F e RelyX U100), exibem os maiores valores na resistência adesiva após o jateamento com óxido de alumínio e termociclagem quando comparados aos 
cimentos convencionais. Isso pode ser explicado pelo fato do ácido fosfórico metacrilato possibilitar uma interação física forte com a superfície (HUMMEL; KERN, 2004; ATSU; KILICARSLAN; KUCUKESMEN; AKA, 2006; LUTHY; LOEFFEL; HAMMERLE, 2006; WOLFART; LEHMANN; WOLFART; KERN, 2007). O emprego de materiais que apresentam monômero MDP em sua composição é considerado fator chave para uma adesão satisfatória da resina à cerâmica de óxido de zircônia, pois o monômero éster fosfato se une diretamente a óxidos metálicos como cromo, alumínio, titânio e zircônio. Agentes de união contendo o monômero 10-metacriloiloxidecil di-hidrogênio fosfato (MDP) também podem se unir quimicamente a óxidos metálicos, ou seja, a aplicação prévia de um primer contendo MDP faz com que o emprego de um cimento contendo o mesmo monômero não seja necessário (YOSHIDA; YAMASHITA; ATSUTA, 2004).

Embora haja um crescente uso das cerâmicas de zircônia nas próteses, levando em consideração suas vantagens. Ainda é necessário o desenvolvimento de uma técnica confiável para a cimentação. Poucos estudos foram publicados a respeito dos métodos de união e dos cimentos usados para gerar uma união estável à zircônia; porém os estudos fornecem dados limitados e resultados controversos (DÉRAND; DÉRAND, 2000; WEGNER; KERN, 2000; KERN; WEGNER, 1998; PIWOWARCZYK; LAUER; SORENSEN, 2005).

Por isso, é importante avaliar a resistência de união entre a zircônia estabilizada por ítrio e o agente cimentante depois de tratamentos de superfície da cerâmica, assim como a interação do tratamento superficial com sistemas adesivos e primers. 


\section{REVISÃO DE}

\section{LITERATURA}




\section{REVISÃO DE LITERATURA}

\subsection{Sistemas Cerâmicos}

Registram-se dados do aparecimento das cerâmicas em 5.500 a.C. na Turquia e 100 a.C. na China, enquanto que na Europa o uso das cerâmicas foi introduzido por volta dos séculos $\mathrm{XV}$ e XVI, devido às negociações com o Oriente (CRAIG; POWERS, 2004).

A palavra "cerâmica" deriva do termo grego keramike, derivação de keramos, que significa argila. Os primeiros indícios das cerâmicas foram encontrados há quase 13 mil anos nas escavações do Vale do Nilo, Egito. Desde o século $X$, a China já dominava a tecnologia da arte em cerâmica, a qual apresentava estrutura interna firme e cor muito branca, chegando à Europa apenas no século XVII onde ficou conhecida como "louças de mesa". A partir de então, os europeus buscaram copiar a composição da porcelana chinesa. Entretanto, somente em 1717 é que se descobriu o segredo dos chineses, que confeccionavam a cerâmica a partir de três componentes básicos: caulim (argila chinesa), sílica (quartzo) e feldspato (mistura de silicatos de alumínio, potássio e sódio) (DELLA BONA; SHEN; ANUSAVICE, 2004).

Em 1774 o francês Alexis Duchateau, insatisfeito com sua prótese total confeccionada com dentes de marfim, decidiu trocá-las por novas próteses de cerâmica, por verificar a durabilidade, resistência ao manchamento e a abrasão deste material quando utilizado em utensílios domésticos. Com o auxílio de Nicholas Dubois de Chemant, a arte das cerâmicas foi introduzida na Odontologia (KELLY; NISHIMURA; CAMPBELL, 1996).

Novas perspectivas também surgiram a partir da introdução da técnica de condicionamento ácido do esmalte por Buonocore (1955) e dos avanços obtidos com o desenvolvimento dos sistemas resinosos para fixação a partir da resina composta de Bowen (1963). Com isso, as técnicas de cimentação adesiva tornaram-se mais confiáveis para restaurações indiretas, melhorando os resultados clínicos.

As cerâmicas são altamente estéticas e capazes de reproduzir grande parte das características dos dentes naturais, são caracterizadas por duas 
fases: uma fase cristalina circundada por uma fase vítrea. A matriz vitrosa é composta por uma cadeia básica de óxido de silício $\left(\mathrm{SiO}_{4}\right)$, sendo que a proporção Si:O está relacionada com a viscosidade e expansão térmica da porcelana (DELLA BONA; SHEN; ANUSAVICE, 2004). Já a quantidade e natureza da fase cristalina ditam suas propriedades mecânicas e ópticas (CRAIG; POWERS, 2004). A partir de sua composição básica, sejam vítreas ou feldspáticas, foram adicionados outros componentes, modificando-se assim as propriedades físicas e ópticas dos diversos sistemas disponíveis. Tais componentes agregados objetivam melhorar as propriedades de cor, opacidade, opalescência e translucidez, além de reduzir a temperatura de fusão ou modificar os coeficientes de expansão e contração (SUÁREZ; LOZANO; PAZ SALIDO; MARTÍNEZ, 2004).

A grande desvantagem das porcelanas é a sua maior friabilidade e falta de resistência, de modo que a principal preocupação nas pesquisas foi procurar diminuir esta suscetibilidade, seja por modificações na própria estrutura da porcelana ou por meio de uma infra-estrutura rígida que pudesse suportar a porcelana de cobertura frágil (BOTTINO; QUINTAS; MIYASHITA; GIANNINI, 2001). A introdução de sistemas cerâmicos com diferentes composições, combinada com o uso de novas técnicas laboratoriais, tem resultado em melhorias nas propriedades mecânicas e estéticas desses materiais. Nas últimas décadas, surgiram os sistemas cerâmicos reforçados, com diferentes técnicas de processamento (HOLAND; SCHWEIGER; FRANK; RHEINBERGER, 2000).

Em 1965, McLean \& Hughes desenvolveram a primeira cerâmica reforçada, modificando a fase cristalina com a adição de cristais de alumina, proporcionando duas vezes mais resistência à fratura quando comparadas às cerâmicas feldspáticas convencionais. A primeira marca comercializada foi 0 In-Ceram® (Vita) introduzida por Sadoun em 1985. Em 1991, foi desenvolvida uma cerâmica que usa como reforço cristais de leucita (35-55\% - Sistema IPS Empress I - E1), denominada de IPS Empress (Ivoclar North América, Amherst, NY, EUA). São processadas por injeção em moldes obtidos pela técnica da cera perdida (McLEAN, 2001). Em 1998, o sistema IPS-Empress teve sua composição cristalina alterada para dissilicato de lítio (60-65\% Sistema IPS Empress II - E2), passando a se chamar IPS-Empress 2 (VAN 
NOORT, 2004). Em 1993, foi desenvolvido o sistema Procera, que utiliza a técnica CAD-CAM (do inglês, computer aided design/computeraided manufacturing) para produção de coroas totais de cerâmica (FRACISCHONE \& VASCONSELOS, 2002). Outros sistemas cerâmicos estão disponíveis no mercado. Dentre os sistemas disponíveis, destacam-se os sistemas CEREC 1, 2 e 3 (Sirona), CELAY (VITA Zahnfabrik), Cercon (Dentsply/Ceramco), Lava All-Ceramic System (3M/ESPE) e IPS e.Max (GOMES; ASSUNÇÃO; ROCHA; SANTOS, 2008).

\subsection{Sistema Procera: Sistema Cerâmico Reforçado}

Foi entre os anos de 1983 e 1987 que o dentista e engenheiro Matts Andersson (Suécia), inspirado no trabalho de Per-Ingvar Branemark com o titânio, idealizou a construção de coroas utilizando esse material, mas encontrou grande dificuldade em fundir o titânio, além da falta de precisão. Com esses problemas próprios do material e da sua manipulação, ele desenvolveu um método que, utilizando "micro-maquinarias", conseguiu produzir infra-estruturas com alta precisão e em escala industrial. Em 1984 o primeiro protótipo dessa máquina estava pronto. Em 1987, Andersson entrou em contato com a Nobelpharma, em Gotemburgo, na Suécia, precisando de uma parceria industrial. Em janeiro de 1988, a Nobelpharma comprou o projeto "Procera". Andersson continuou trabalhando com a empresa e em 1991 a primeira coroa Procera All Ceram foi produzida. Logo depois, em 1992 a Nobelpharma se uniu à Sandvik $A B$ para melhorar o desenvolvimento das cerâmicas para Odontologia, e em 1993 a nova tecnologia dos "scanners" foi introduzida ao processo de produção (FRANCISCHONE; VASCONCELOS, 2002; NOBEL BIOCARE).

O sistema Procera ${ }^{\circledR}$ utiliza tecnologia CAD/CAM (do inglês, computer aided design/computeraided manufacturing) na produção industrial de infraestruturas para coroas cerâmicas e prótese para implante em cerâmica e titânio (FRANCISCHONE; VASCONCELOS, 2002). As infra-estruturas cerâmicas são compostas de óxidos de alumíno de alta pureza $\left(99,5 \%\right.$ de $\left.\mathrm{Al}_{2} \mathrm{O}_{3}\right)$, de zircônia (> 99\% de $\mathrm{ZrO}_{2}+\mathrm{YO}_{3}+\mathrm{HfO}_{2}$ ), ambas densamente sintetizadas, e de titânio, comercialmente puro (NOBEL BIOCARE). 
Os copings do sistema Procera ${ }^{\circledR}$ são indicados para qualquer região da cavidade oral anterior ou posterior e são apoiados sobre dentes ou implantes com copings unitários ou prótese fixa de quatro elementos (FRANCISCHONE; VASCONCELOS, 2002).

A leitura do troquel original é realizada por meio de um scanner mecânico. A leitura completa do troquel leva, aproximadamente, três minutos, gerando, no final, cerca de 30 mil a 50 mil pontos de leitura. Todos os dados são armazenados em um computador (NOBEL BIOCARE).

O processamento dos dados é feito por um programa específico do sistema Procera ${ }^{\circledR}$, que utiliza o sistema operacional Windows, as informações obtidas do scanner são convertidas em pontos tridimensionais que reproduzirão, com alta fidelidade, os contornos do preparo dentário na tela do computador. Com esse software é possível determinar as margens do preparo, estabelecer a espessura do coping e 0 perfil de emergência. (FRANSCISCHONE; VASCONCELOS, 2002; NOBEL BIOCARE).

Depois de definidos todos os detalhes necessários à confecção do coping, essas informações são enviadas, pela internet, à central de produção para a montagem da infra-estrutura. A duplicação dos troquéis é feita nas centrais de confecção da infra-estrutura, em Estocolmo, na Suécia, ou nos Estados Unidos (Fair Law); são construídos dois troquéis, por meio de um sistema de usinagem (CAM), utilizando-se as informações obtidas do troquel original. Um troquel de trabalho é confeccionado com dimensões aumentadas, $15 \%$ a $20 \%$ maiores que o troquel original. O coping com tamanho original e a cópia do troquel são analisados pelo microscópio para que sejam identificadas cor, microfraturas e integridade de adaptação. Concluída a verificação, esse material é enviado para o laboratório protético (NOBEL BIOCARE).

Uma das principais vantagens das infra-estruturas do sistema Procera ${ }^{\circledR}$, é a sua elevada resistência a fraturas sob pressão, comparada com os outros tipos de infra-estruturas utilizadas para próteses livres de metal. Assim as infraestruturas de IPS Empress 2 suportam por volta de $400 \mathrm{MPa}$; o InCeram Zircônia resiste $620 \mathrm{MPa}$; e a Procera ${ }^{\circledR}$ AllCeram até $687 \mathrm{MPa}$; estimativas que foram calculadas usando métodos de flexão biaxial e uniaxial de 2, 3 e 4 pontos. (PALLIS; GRIGGS; WOODY; GUILLEN; MILLER, 2004). 
A estrutura Procera Zircônia está indicada para as mais variadas situações clínicas, desde coroas unitárias, pilares, a reabilitações complexas com pontes e implantes (NOBEL BIOCARE). Oden, Andersson, KrystekOndracek, Magnusson, em 1998, através de um estudo longitudinal, observaram por 5 anos coroas de Procera em função, e concluíram que esse tipo de infra-estrutura pode ser usado em todas as áreas da boca, pois das 100 coroas realizadas, apenas 3 apresentaram problemas após o período citado.

\subsection{Zircônia Tetragonal Policristalina Estabilizada por Ítrio}

Zircônia, o dióxido metálico $\left(\mathrm{ZrO}_{2}\right)$, foi identificado em 1789 pelo químico alemão Martin Heinrich Klaproth. Investigações recentes com a zircônia como biomaterial focam-se em cerâmica de zircônia-Ítrio, caracterizada por microestruturas de granulação fina, conhecidas por policristais de zircônia tetragonais (TZP - Tetragonal Zirconia Polycristals) (NOBEL BIOCARE).

A evolução de materiais à base de zircônia tetragonal policristalina estabilizada por ítrio (Y-TZP) introduziu uma nova classe de cerâmica odontológica no mercado (LUTHY; LOEFFEL; HAMMERLE, 2006). Embora a Y-TZP venha sendo usada como biomaterial cerâmico em aplicações médicas desde os anos sessenta, seu uso na Odontologia é relativamente recente, e ocorreu depois dos avanços na tecnologia de CAD-CAM (projeto assistido por computador/fabricação) (PICONI; MACCAURO, 1999; GUAZZATO; ALBAKRY; RINGER; SWAIN, 2004; WOLFART; LEHMANN; WOLFART; KERN, 2007; BLATZ; SADAN; MARTIN; LANG, 2004).

Nos últimos anos, novos materiais e técnicas foram desenvolvidos e muita atenção tem sido direcionada na confecção de coroas cerâmicas com melhores propriedades mecânicas e estéticas (McLEAN, 2001). O primeiro estudo com cerâmicas de zircônia que verificou o aumento da resistência mecânica e da tenacidade à fratura foi feito em 1975 por Garvie, Hannink e Pascoe que verificaram o aumento de volume e o cisalhamento promovido pela transformação martensítica. A boa estabilidade dimensional e química das cerâmicas Y-TZP, aliada à resistência mecânica da mesma magnitude das ligas de aço inoxidável deu origem ao interesse no uso da zircônia como biomaterial cerâmico (PICONI; MACCAURO, 1999). 
A zircônia pura apresenta três fases: monoclínica, estável até cerca de $1170{ }^{\circ} \mathrm{C}$; tetragonal de 1170 até $2370{ }^{\circ} \mathrm{C}$; e cúbica de $2370{ }^{\circ} \mathrm{C}$ até a temperatura de fusão $\left(2680{ }^{\circ} \mathrm{C}\right)$ (PICONI; MACCAURO, 1999). A zircônia tetragonal policristalina estabilizada por ítrio (Y-TZP) é um material cerâmico com propriedades mecânicas superiores às das demais cerâmicas odontológicas (KOSMAC; OBLAK; JEVNIKAR; FUNDUK; MARION, 1999). A YTZP é sinterizada ao redor de $1500^{\circ} \mathrm{C}$ e apresenta tamanho de grão fino (da ordem de alguns micrômetros) e baixíssima porosidade, o que resulta em elevada resistência à flexão (até $\sim \mathrm{GPa})$, tenacidade à fratura $\left(\sim 10 \mathrm{MPa} \cdot \mathrm{m}^{1 / 2}\right)$, dureza ( 14GPa) e resistência ao desgaste erosivo (PICONI; MACCAURO, 1999).

As propriedades mecânicas da Y-TZP tais como a resistência flexural e a fratura são consideravelmente superiores às das outras cerâmicas dentais. 0 seu módulo de elasticidade é de, aproximadamente, 200MPa, e a resistência flexural, de 820MPa. Estas propriedades são superiores às exibidas por outra cerâmica de alta resistência (GUAZZATO; ALBAKRY; RINGER; SWAIN, 2004). Os materiais de Y-TZP também exibem resistência à fratura maior que $2.000 \mathrm{~N}$, que é quase duas vezes o valor obtido para materiais a base de alumina e pelo menos três vezes o valor demonstrado pela cerâmica de dissilicato de lítio (TINSCHERT; NATT; MAUTSCH; SPIEKERMANN; ANUSAVICE, 2001).

Diante das evidências do papel da zircônia como agente tenacificador de cerâmicas, vários sistemas matriz-cerâmica-zircônia têm sido estudados. Tal reforço é conseqüência da transformação induzida por tensão da fase tetragonal para fase monoclínica das partículas de zircônia, a qual é acompanhada de uma expansão volumétrica de 3-4\% em volume, o que induz tensões de compressão que irão se opor à rachadura e dificultar sua propagação (PICONI; MACCAURO, 1999; CHEVALIER; OLAGNON; FANTOZZI, 1999).

Essa variação dimensional tende a remover a energia da trinca podendo, inclusive, interromper a sua propagação na linha de fratura. Esse mecanismo é denominado "tenacificação por transformação" ou "transformação martensítica". A mudança de volume também cria uma força compressiva em volta da partícula, que produz uma inibição adicional para o crescimento da trinca. $A$ habilidade de barrar a propagação de trincas na estrutura da zircônia mimetiza 
o efeito presente nos dentes naturais, em que as trincas são bloqueadas na interface esmalte-dentina (GUAZZATO; QUACH; ALBAKRY; SWAIN, 2005; PICONI \& MACCAURO, 1999).

Apesar dessa capacidade de barrar a propagação de trincas, Guazzato Quach; Albakry; Swain, em 2005, verificaram que o impacto das partículas de jateamento com óxido de alumínio causa danos à superfície de Y-TZP, caracterizados por um extenso desgaste erosivo e pela presença de trincas na lateral. Apesar das falhas induzidas pelo jateamento, este procedimento aumentou a resistência flexural dos espécimes. Essa melhora na resistência flexural está relacionada à quantidade de fase monoclínica encontrada após o jateamento $(9,5 \%)$.

A preocupação maior referente ao uso da zircônia é a sua degradação em baixas temperaturas $\left(<300 \_\mathrm{C}\right)$, na presença de umidade. $\mathrm{O}$ envelhecimento ocorre por uma lenta transformação da fase tetragonal para fase monoclínica, que é estável na presença de água ou vapor de água. A degradação em baixa temperatura da Y-TZP inicia-se na superfície policristalina e progride em direção ao interior do material. A transformação de um grão provoca o aumento no volume causando tensões nos grãos vizinhos e provocando o aparecimento de microtrincas. A penetração de água provoca uma degradação superficial transformando os grãos vizinhos. A transformação inicial de grãos específicos pode ser devido ao estado de desequilíbrio microestrutural ocasionado por diferentes fatores: tamanho maior de grãos, por uma menor quantidade de ítrio, por uma orientação específica da superfície, a presença de tensão residual ou a presença de fase cúbica (CHEVALIER; DEVILLE; MÜNCH, 2004).

Recentemente, a aplicabilidade da cerâmica Y-TZP como biomaterial tem sido questionada, depois da constatação de que próteses com cabeças de fêmur deste material apresentaram 400 casos de falha em curto período no ano de 2001, provavelmente devido ao processo de desestabilização (envelhecimento) a baixa temperatura $\left(37^{\circ} \mathrm{C}\right.$, temperatura do fluido corpóreo) (CHEVALIER, 2006). É difícil falar em ausência de envelhecimento, já que a fase monoclínica é seu estado de equilíbrio (CHEVALIER, 2006). 


\subsection{Adesão à Y-TZP: Tratamentos de Superfície e Agentes de União}

De acordo com Piwowarczyk, Lauer \& Sorensen (2005), não é possível alcançar uma união durável a cerâmica de zircônia usando cimento de fosfato de zinco, cimento de ionômero de vidro convencional e modificado por resina. Consideráveis diferenças na resistência adesiva ao cisalhamento foram observadas entre os cimentos avaliados. Entretanto, existem poucos estudos sobre os métodos de união das cerâmicas Y-TZP com os cimentos resinosos (WEGNER; KERN, 2000; BLATZ; SADAN; MARTIN; LANG, 2004). A obtenção de uma união satisfatória entre o agente cimentante e a superfície cerâmica requer um pré-tratamento (OZCAN; VALLITTU, 2003; OZCAN, 2002).

Ao contrário das cerâmicas odontológicas passíveis de condicionamento, os materiais Y-TZP são compostos de pequenas partículas sem nenhuma fase vítrea nas bordas dos cristalitos (LUTHARDT et al., 2002). Por esse motivo, muitos trabalhos visam desenvolver técnicas de retenção das resinas às infra-estruturas cerâmicas, já que a superfície interna das infraestruturas, apesar de apresentar certo grau de irregularidades, não retém a resina composta satisfatoriamente e, conseqüentemente, a prótese em posição quando submetida a grandes esforços (LUTHARDT et al., 2002).

A superfície do Procera AllZirkon tem uma rugosidade única devido ao processo de manufatura. Esta microrrugosidade pode influenciar o entrelaçamento micromecânico de união dos agentes cimentantes (BLATZ; SADAN; KERN, 2003).

O emprego de materiais resinosos para cimentação pode aumentar a resistência à fratura e melhorar o desempenho clínico das restaurações (BLATZ; SADAN; KERN, 2003). Os procedimentos de cimentação adesiva, que incluem o condicionamento com ácido fluorídrico e a aplicação de silanos na superfície do material previamente à inserção do cimento resinoso, são ineficazes nas cerâmicas Y-TZP (DERAND; MOLIN; KVAM, 2005; KERN; WEGNER, 1998; YOSHIDA; YAMASHITA; ATSUTA, 2004).

condicionamento com ácido fluorídrico é indicado apenas para superfícies com componentes vítreos, portanto, o ácido é incapaz de criar microrretenções nas 
superfícies internas das peças em Y-TZP (DERAND; MOLIN; KVAM, 2005; YOSHIDA; YAMASHITA; ATSUTA, 2004). Já os silanos são recomendados para formar uma união química entre a sílica presente na superfície cerâmica e a matriz orgânica dos materiais resinosos; procedimento também descartado para sistemas de óxido de zircônia devido à ausência da sílica em sua composição (DERAND; MOLIN; KVAM, 2005; KERN; WEGNER 1998).

Vários mecanismos foram sendo introduzidos com o objetivo de melhorar a adesão. Dentre as alternativas propostas, pode-se incluir o

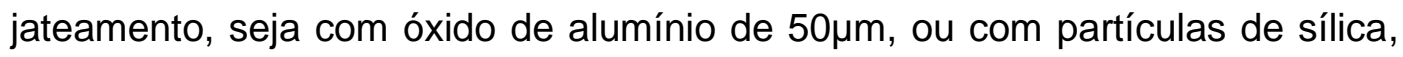
que podem variar de 30 a $110 \mu \mathrm{m}$, representados pelos sistemas Cojet e Rocatec (3M ESPE), respectivamente (ATSU; KILICARSLAN; KUCUKESMEN; AKA, 2006; VALANDRO; DELLA BONA; BOTTINO; NEISSER, 2005); a deposição de estanho; o condicionamento com ácidos, o tratamento térmico, a aplicação de primers ou condicionadores para metal (YOSHIDA; TAIRA; SAWASE; ATSUTA, 1997) ou uma associação entre métodos.

$\mathrm{O}$ efeito do jateamento com partículas de $\mathrm{Al}_{2} \mathrm{O}_{3}$ na superfície interna da cerâmica Y-TZP é objeto de controvérsia na literatura (KOSMAC; OBLAK; JEVNIKAR; FUNDUK; MARION, 1999; PIWOWARCZYK; LAUER; SORENSEN, 2005; WOLFART; LEHMANN; WOLFART; KERN, 2007; ZHANG; LAWN; REKOW; THOMPSON, 2004). De acordo com Zhang; Lawn; Rekow; Thompson, em 2004a, o jateamento pode criar microtrincas na superfície da cerâmica, enfraquecendo o material ao longo do tempo. Por outro lado, o jateamento com óxido de alumínio é um dos tratamentos de superfície de escolha para os materiais cerâmicos de alta resistência (BLATZ; SADAN; KERN, 2003; KERN; WEGNER, 1998; WEGNER; KERN, 2000; WOLFART; LEHMANN; WOLFART; KERN, 2007). Segundo Wolfart; Lehmann; Wolfart; Kern, em 2007, este fato indica que algum tipo de alteração superficial é imprescindível para se atingir união durável à zircônia.

Para a união da zircônia à estrutura dental, o procedimento considerado padrão para as cerâmicas odontológicas, ou seja, jateamento com óxido de alumínio, aplicação de silano e os procedimentos adesivos convencionais foi testado (ÖZCAN; VALLITTU, 2003). Entretanto, apesar dos valores iniciais razoáveis de resistência à tração, as amostras falham espontaneamente após armazenagem em água e termociclagem (KERN; WEGNER, 1998; WEGNER; 
KERN, 2000). Adicionalmente, o estudo feito por Zhang; Lawn; Rekow; Thompson, em 2004a, evidenciou que o jateamento com óxido de alumínio por 5 segundos reduz a resistência da zircônia em cerca de 25\% quando sob carregamento cíclico, devido à geração de microtrincas que resultam em falha precoce do material. O dano causado pelo jateamento com óxido de alumínio é da ordem de $1 \mathrm{~N}$ aproximadamente, o que poderia comprometer a longevidade das restaurações em Y-TZP submetidas ao jateamento prévio (ZHANG; LAWN, 2005). O jateamento das peças de Y-TZP pode induzir a transformação tetragonal-monoclínica e a formação de falhas na superfície, o que poderia ser prejudicial ao desempenho em longo prazo, apesar do aumento imediato da resistência adesiva devido à transformação induzida dos esforços compressivos (GUAZATTO; ALBAKRY; RINGER; SWAIN, 2004).

Zhang; Lawn; Rekow; Thompson, em 2004b, avaliaram o efeito do carregamento cíclico sobre a tolerância à propagação de trincas de duas cerâmicas, uma à base de óxido de zircônia e uma à base de alumina. Os autores analisaram o desenvolvimento de falha catastrófica, ou seja, trinca radial (radial crack) que se origina a partir da interface com a resina epóxica, o que, clinicamente, significaria a fratura da restauração cerâmica. Os resultados evidenciaram que em um mesmo período de tempo, Y-TZP suportaria carregamentos mais altos que a alumina. A menor tendência à propagação de trincas parece estar relacionada ao menor tamanho dos cristais.

O jateamento com sílica, seguido da silanização, também tem sido indicado para melhorar a resistência adesiva das estruturas de alumina e zircônia (ATSU; KILICARSLAN; KUCUKESMEN; AKA, 2006; OZCAN; VALLITTU, 2003; ERNST; COHNEN; STENDER; WILLERSHAUSEN, 2005; VALANDRO; DELLA BONA; BOTTINO; NEISSER, 2005). O primeiro método de deposição de sílica foi descrito em 1984, por Tiller et al., que desenvolveram o método do silicoater, que consiste em depositar sobre a superfície do metal jateado uma camada de óxido de silício (ÖZCAN; PFEIFFER; NERGIZ, 1998).

Esta técnica de jateamento e silanização pode ser conseguida por diferentes métodos (OZCAN 2002; VALANDRO; DELLA BONA; BOTTINO; NEISSER, 2005), como exemplo, os sistemas Rocatec e Cojet (3M ESPE), que 
criam um revestimento triboquímico na superfície jateada (ATSU; KILICARSLAN; KUCUKESMEN; AKA, 2006; VALANDRO; DELLA BONA; BOTTINO; NEISSER, 2005). O objetivo desses sistemas é formar uma fina camada de sílica que contenham grupamentos hidroxila livres suficientes para permitir a união à resina através de um silano. Isso ocorre quando as partículas de sílica coloidal de alta energia batem contra a superfície da peça, causando fusão física de uma camada de sílica na superfície. Essa superfície é então tratada com silano e está pronta para adesão (VAN NOORT, 2004).

O sistema Rocatec foi introduzido na Alemanha, em 1989, e esse método triboquímico envolve a criação de ligações químicas aplicando energia mecânica, através do jateamento. O sistema Rocatec de deposição de sílica é executado em três fases: $1^{\circ}$ - jateamento com partículas de $\mathrm{Al}_{2} \mathrm{O}_{3}$ (RocatecPré); $2^{\circ}$ - é jateamento com o óxido de alumínio modificado por ácido silícico (Rocatec-Plus); $3^{\circ}$ - silanização com Rocatec-Sil (KERN; THOMPSON, 1995). Ozcan \& Vallittu (2003) mostraram que o jateamento com sílica seguido de silanização pode aumentar significantemente a resistência adesiva para as cerâmicas a base de alumina e zircônia quando comparados com o jateamento com $\mathrm{Al}_{2} \mathrm{O}_{3}$ sozinho. A sílica cria uma fina superfície áspera que aumenta a área de superfície e, melhora a união mecânica e química (OZCAN 2002; OZCAN; VALLITTU, 2003; VALANDRO; DELLA BONA; BOTTINO; NEISSER, 2005; ERNST; COHNEN; STENDER; WILLERSHAUSEN, 2005; ATSU; KILICARSLAN; KUCUKESMEN; AKA, 2006). Além disso, criam uma camada de sílica na superfície da cerâmica, por meio do jateamento em alta velocidade de partículas de óxido de alumínio modificado por sílica, formando uma união química entre a superfície da cerâmica e o agente silano (OZCAN, 2002; BLATZ; SADAN; KERN, 2003; OZCAN; VALLITTU, 2003; VALANDRO; DELLA BONA; BOTTINO; NEISSER, 2005; ERNST; COHNEN; STENDER; WILLERSHAUSEN, 2005; ATSU; KILICARSLAN; KUCUKESMEN; AKA, 2006).

A ceramização da superfície jateada ocorre no impacto das partículas, sendo que a transmissão de impulsos e energia gera temperaturas muito elevadas a nível local. Isto provoca uma excitação tão forte dos átomos e moléculas das superfícies do substrato atingido, que pode ser chamado de triboplasma. Nesse processo, $\mathrm{O} \mathrm{SiO}_{2}$ é implantado na superfície, numa profundidade de até $15 \mu \mathrm{m}$, ao mesmo tempo que se aglutina à superfície, em 
forma de ilhas. A alta energia necessária para tanto provém da aceleração das partículas até $1.000 \mathrm{~km} / \mathrm{h}$, decorrente da configuração geométrica do ejetor e de uma pressão mínima de jateamento de 2,8 bar. A silanização permite que se estabeleça uma união química entre as superfícies revestidas com a resina. Esse agente adesivo silício orgânico contém os grupos metacrílicos adequados para a ligação com o material de revestimento. Só assim, pode-se obter uma união química entre a superfície silicática inorgânica e a resina orgânica. Essa resina pode ser uma resina para revestimento ou qualquer outro sistema monomérico metacrilato (3M/ESPE).

De acordo com Kumbuloglu, Lassila \& Vallittu (2006) o jateamento com partículas com $\mathrm{SiO}_{2}$ (Rocatec) rendeu em forças de união ligeiramente maior do que a obtida com o jateamento com partículas de $\mathrm{Al}_{2} \mathrm{O}_{3}$, portanto não houve diferença estatisticamente significante entre os dois diferentes sistemas de jateamento. Além disso, o armazenamento para uma semana ou a termociclagem, não afetaram significativamente as propriedades de união dos cimentos avaliados (Panavia $F$ e de RelyX Unicem) à zircônia.

O silano contribui com o aumento da resistência de união, pois forma uma ligação química com o cimento resinoso por meio de ligações cruzadas com os grupamentos metacrilatos, além de aumentar a energia de superfície e melhorar o molhamento (BLATZ; SADAN; KERN, 2003). O mecanismo de união química do silano com o substrato metálico reside na afinidade do elemento silício, principal componente deste tipo de condicionador, com os óxidos metálicos (COBB; VARGAS; FRIDRICH; BOUSCHLICHER, 2000).

Os primers metálicos foram desenvolvidos como uma alternativa para promover uma união durável às ligas de metal nobre (YOSHIDA; KAMADA; ATSUTA, 2001; SILIKAS; WINCOTT; VAUGHAN; WATTS; ELIADES, 2007). Os primers são compostos por um monômero com estrutura bifuncional, com uma extremidade contendo um grupo funcional metacril ou similar para a união da resina, e a outra extremidade contendo grupamentos mercaptano ou tiol para união à liga (VAN NOORT, 2004). O monômero 6-VBATDT (4-vinylbenzyln-propyl amino-1,3,5-triazine-2,4-dithione) foi o primeiro produto introduzido como um agente de união entre os monômeros à base de metacrilato e as ligas de metal nobre (SILIKAS; WINCOTT; VAUGHAN; WATTS; ELIADES, 2007). 
Atualmente, diferentes tipos de cimentos estão disponíveis no mercado. Estes incluem o cimento de fosfato de zinco, cimento de ionômero de vidro convencional e modificado por resina, cimentos resinosos e um material recentemente desenvolvido, que é o cimento resinoso auto-adesivo. Entretanto, a cimentação convencional, a base de cimento de fosfato de zinco, cimento de ionômero de vidro convencional e modificado por resina, é instável ao longo do tempo às estruturas de zircônia. Esses cimentos ofereceram uma baixa resistência adesiva inicial após os tratamentos da superfície com óxido de alumínio e do revestimento triboquímico com sílica. Após o armazenamento em água e termociclagem por 14 dias, a resistência adesiva diminuiu ainda mais ou houve a desunião dos espécimes. Já o objetivo no desenvolvimento do cimento resinoso auto-adesivo foi combinar o fácil manuseamento e a ausência de pré-tratamento encontrado nos cimentos de ionômero de vidro com as propriedades mecânicas favoráveis, estética e união satisfatória oferecida pelos cimentos resinosos (PIWOWARCZYK; LAUER; SORENSEN, 2005).

Segundo Luthy, Loeffel, Hammerle (2006) a união dos cimentos resinosos convencionais, a base de BisGMA foi considerada muito baixa para assegurar uma boa cimentação clínica (<3MPa). O cimento a base de BisGMA após a termociclagem mostrou uma grande redução na resistência adesiva à zircônia (DERAND; DERAND,2000; KERN; WEGNER, 1998; LUTHY; LOEFFEL; HAMMERLE, 2006 ). Entretanto, com o uso do Rocatec, a redução na resistência adesiva após a termociclagem (22,8 MPa para 18,9 MPa) não foi significante (LUTHY; LOEFFEL; HAMMERLE, 2006). Os cimentos resinosos a base de ácido fosfórico metacrilato (Panavia F e RelyX Unicem), exibiram os maiores valores na resistência adesiva após o jateamento com óxido de alumínio quando comparados aos cimentos convencionais. Isso pode ser explicado pelo fato do ácido fosfórico metacrilato possibilitar uma interação física forte com a superfície da alumina (PIWOWARCZYK; LAUER; SORENSEN, 2004).

Kern \& Wegner (1998) encontraram uma redução significante na resistência adesiva após 150 dias de armazenamento e termociclagem com 37.500 ciclos nos cimentos a base de MDP, independente do tratamento de superfície empregado. Já nos cimentos a base de BisGMA, houve a desunião espontânea dos espécimes ao longo do tempo.Após 14 dias de termociclagem, 
o cimento resinoso a base de ácido fosfórico metacrilato (RelyX Unicem) mostrou um melhor desempenho, independente do tratamento de superfície utilizado (Rocatec ou jateamento com óxido de alumínio), mesmo quando comparado ao cimento a base de MDP (PIWOWARCZYK, LAUER, SORENSEN, 2005). Outros estudos consideram o emprego de materiais que apresentam monômero MDP como fator chave para uma adesão satisfatória da resina à cerâmica densa de óxido de zircônia (KERN; WEGNER, 1998; WEGNER; KERN, 2000; BLATZ; SADAN; MARTIN; LANG, 2004), pois o MDP se liga à camada de óxidos presente na superfície destas cerâmicas (KERN; WEGNER, 1998; WEGNER; KERN, 2000; HUMMEL; KERN, 2004). Além disso, a sua associação com o jateamento de óxido de alumínio também é efetiva (BLATZ; SADAN; KERN, 2003).

Grupamentos do éster fosfato presentes em alguns cimentos resinosos e primers para metal parecem capazes de se unir a óxidos metálicos, como o óxido de zircônio (KERN; WEGNER, 1998; HUMMEL; KERN, 2004). Em função da estrutura química das cerâmicas Y-TZP, basicamente composta por óxido de zircônia, é possível que estes materiais interajam quimicamente com a superfície cerâmica, melhorando a união com os cimentos resinosos (KERN; WEGNER, 1998; ATSU; KILICARSLAN; KUCUKESMEN; AKA, 2006; LUTHY; LOEFFEL; HAMMERLE, 2006; YOSHIDA; TSUO; ATSUTA, 2006; WOLFART; LEHMANN; WOLFART; KERN, 2007).

Adicionalmente existem dúvidas sobre os benefícios da aplicação de um agente de união sobre esta superfície depois de ser tratada e antes de receber o agente cimentante (SOARES; SOARES; PEREIRA; FONSECA, 2005), ou seja, como ocorre a interação entre os sistemas adesivos comuns e/ou primers metálicos na união aos óxidos metálicos e cerâmicos (alumina e zircônia).

\subsection{Teste de Cisalhamento}

Um problema no que se refere às pesquisas na área de adesão é a falta de padronização entre os estudos realizados, impossibilitando a comparação de resultados entre os mais diversos pesquisadores (RETIEF, 1991). A ISO 
(International Organization for Standardization) preconiza desde 1991 alguns tipos de testes mecânicos, incluindo-se aí os ensaios de tração e cisalhamento.

Os testes mecânicos laboratoriais, geralmente, se fundamentam na aplicação de forças de deslocamento sobre a união, na tentativa de simular os mesmos esforços sofridos pela restauração durante sua função no meio bucal. Tensão é definida como uma força $(F)$ que atua internamente nas partículas constituintes de um corpo, aplicada em área específica. Existem tensões de tração (tendência de alongar o material), tensões de contração (tendem a encurtar o material), de cisalhamento (tendem a torcer ou deslocar uma porção de um corpo sobre o outro), tensões complexas (todas as tensões ao mesmo tempo) e as tensões de flexão (que tendem a dobrar o corpo) (ANUSAVICE, 2005). As forças e tensões exercidas sobre os dentes e restaurações na clínica são, entretanto, de natureza complexa, portanto, nenhum teste simula adequadamente as forças intrabucais (RETIEF, 1991).

Retief (1991) verificou que para avaliar os valores de resistência de união, muitos fatores exercem influência marcante nos resultados, como tipo e face do dente, tempo de estocagem, meio de imersão, preparação da superfície e tipo de teste utilizado. No entanto, as forças exercidas clinicamente sobre as restaurações ou sobre o dente são de natureza complexa, e nem tração ou cisalhamento simulam as forças intra-orais. Em 1991, a ISO por meio da norma TR 11405, promoveu uma tentativa de padronização para os testes de adesão à estrutura dental com o objetivo de padronizá-los. Entre os testes de resistência de união está o teste de tração e o de cisalhamento. Para o teste de cisalhamento, a norma descreve um aparelho constituído por uma luva metálica que aloja a amostra e por uma chapa metálica com $5 \mathrm{~mm}$ de espessura, fixada paralelamente à luva metálica que possui três orifícios com diâmetro de 3, 5 e $10 \mathrm{~mm}$, utilizados de acordo com o tamanho da amostra. Cada orifício possui uma angulação de $45^{\circ}$ e a parte que faz a punção na amostra é plana e com $1 \mathrm{~mm}$ de largura, formando um ângulo reto.

De acordo com, Sinhoreti; Consani; De Goes; Sobrinho; Knowles, em 2001, o teste de cisalhamento preconizado pela ISO, apresenta um complexo de esforços mecânicos como clivagem, tração e compressão na área de união e não apenas o esforço de cisalhamento. Para os autores, o uso de cinzel, bem como, o fio ortodôntico para a realização do carregamento no teste mecânico 
implica em momentos de flexão criados pela mínima distância entre o carregamento e a superfície de união, além de clivagem, tração e compressão. O uso de dispositivos que envolvam completamente o corpo-de-prova tais como fitas de maior área diminuiriam esses esforços complexos, criando assim, maior concentração de tensões tangenciais na região de união, promovendo melhor deslizamento entre planos.

O teste de cisalhamento é um dos mais simples e amplamente utilizados. No ensaio de cisalhamento, a força de trabalho é aplicada paralelamente à superfície do dente (OILO, 1993). Para a realização deste ensaio, espécimes em forma de cilindro e com diâmetro variando de 3 a $4 \mathrm{~mm}$ são necessários. O teste pode ser realizado por meio de uma haste metálica ou uma alça de fio de aço, justapostas o mais próximo possível da interface adesiva (GARCIA; D'ALPINO; TERADA; CARVALHO, 2002). De acordo com Oilo (1993), o ensaio de resistência ao cisalhamento, em alguns casos, exibe resultados mais altos do que o teste de resistência à tração, mas seguindo uma mesma classificação para os mesmos produtos. No teste de cisalhamento, quanto mais distante o ponto de aplicação da tensão em relação à região de união, maior o momento de flexão, resultando não somente em tensões de cisalhamento, mas sim de tração e compressão. As tensões são sensíveis à geometria do carregamento, forma e tamanho do aderente e seu módulo de elasticidade relativo (VAN NOORT; NOROOZI; HOWARD; CARDEW, 1989).

Embora sujeitos a críticas, os testes de cisalhamento são os testes mais freqüentemente empregados pelos autores para a avaliação da resistência adesiva de materiais à estrutura dentária. Em um levantamento de 50 trabalhos publicados, Al-Salehi, Burke (1997) verificaram que $80 \%$ empregaram os testes de cisalhamento, nas suas diversas formas, para a avaliação da resistência adesiva. Isso provavelmente se explica pela simplicidade do método e facilidade de adequação aos diferentes equipamentos disponíveis nos diversos laboratórios (GARCIA; D'ALPINO; TERADA; CARVALHO, 2002).

De acordo com Dunn, Söderholm (2001), tanto o teste de cisalhamento com alça de fio ortodôntico quanto o método de resistência flexional de quatro pontos podem ser utilizados para avaliação da interface adesiva, já que não apresentam diferença significante nos resultados. Na comparação do teste de cisalhamento do método de fio ortodôntico com o de ponta de faca, 
Cardoso; Meloncini; Placido; Lima; Tavares, em 2003, encontraram diferenças entre os dois métodos, entretanto, a desproporção quantitativa entre as magnitudes de adesão para cada sistema adesivo foi mantida. Assim como, Sinhoreti; Consani; DeGoes; Sobrinho; Knowles, em 2001, compararam a influência dos sistemas de carregamento fio ortodôntico, fita de aço inoxidável e cinzel, usados em testes de união ao cisalhamento e verificaram que as variações nas metodologias dos testes resultaram em diferentes valores de resistência ao cisalhamento. Os valores dependem de uma complexa combinação de esforços e resultantes produzidas durante o carregamento das amostras.

DeHoff, Anusavice, Wang, em 1995, questionaram se o teste de cisalhamento realmente causa uma fratura por cisalhamento na interface ou a fratura é causada por forças de tração incontroladas em um dos materiais. Através da análise de elemento finito em um plano tridimensional verificaram que há uma grande concentração de tensões na interface próxima à área de aplicação da força, o uso de fio ao invés de cinzel é preferível, visto que reduz a concentração de tensões próximas à interface; os testes não consideram fatores críticos tais como dependência de tempo, distribuição de falhas e instabilidade de trincas; e o fato de que muitas falhas clínicas ocorrerem mediante cargas cíclicas.

Os testes de resistência de união, embora não perfeitos, têm auxiliado no desenvolvimento e melhoramento dos sistemas adesivos e técnicas restauradoras. Entretanto, esses testes estão na dependência do método usado e os valores obtidos devem ser cuidadosamente interpretados, pois os fatores que levam uma interface adesiva a resistir à fratura são complexos e não podem simplesmente ser correlacionados com valores numéricos. Entretanto, novos métodos de teste deveriam ser desenvolvidos para auxiliar os pesquisadores no avanço dos materiais odontológicos (SUDSANGIAM \& VAN NOORT, 1999).

Portanto, as evidências existentes a respeito da união de cimentos resinosos a cerâmicas à base de Y-TZP indicam que uma técnica com melhor previsibilidade e durabilidade ainda não está definida. Por este motivo, os procedimentos de união a cerâmicas à base de Y-TZP devem ser testados em estudos in vitro, visando identificar materiais e técnicas eficazes. 


\section{PROPOSIÇÃO}




\section{PROPOSIÇÃO}

Este estudo in vitro se propõe a avaliar a resistência adesiva de um cimento resinoso auto-adesivo à infra-estrutura de zircônia, em função de diferentes agentes de união e condições de superfície.

Os objetivos específicos são:

- Avaliar a influência de diferentes tratamentos de superfície na resistência de união à zircônia.

- Analisar a ação de um sistema adesivo na resistência de união à zircônia.

- Analisar a ação de primers metálico na resistência de união à zircônia.

- Verificar a associação de um tratamento de superfície com um agente de união (primers e sistema adesivo) na resistência de união à zircônia.

\section{HIPÓTESES NULAS:}

- Os diferentes tratamentos superficiais não influenciam nos valores de resistência de união do agente cimentante à zircônia.

- A utilização de um sistema adesivo não interfere na resistência de união do agente cimentante à zircônia.

- A utilização de primers metálico não interfere na resistência de união do agente cimentante à zircônia.

- A associação de um tratamento de superfície com um agente de união (primers e sistema adesivo) não interfere na resistência de união à zircônia. 


\section{MATERLAL E MÉTODOS}

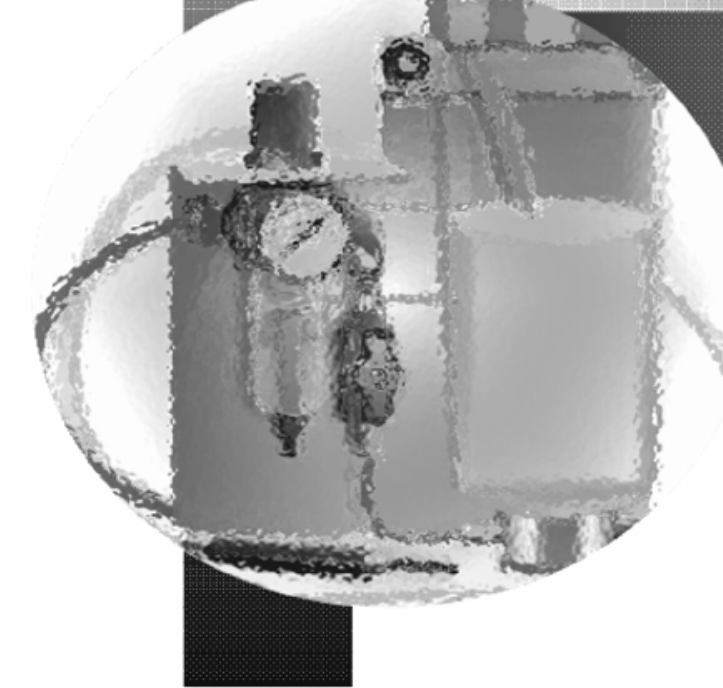




\section{MATERIAL E MÉTODOS}

\subsection{MATERIAIS UTILIZADOS}

Para a realização deste estudo, os espécimes foram confeccionados com cilindros $\left(3,5 \mathrm{~mm}\right.$ de diâmetro) de PROCERA ${ }^{\circledR}$ ZIRCÔNIA (NOBEL BIOCARE, Suécia). Diferentes condições de superfície da zircônia em função de alguns agentes de união foram analisadas, por meio do uso de um cimento resinoso auto-adesivo.

Para isso, foram empregados o cimento resinoso auto-adesivo RelyX U100/3M ESPE (Figura 1); o sistema adesivo, Clearfil SE Bond/Kuraray Co. (Figura 2); os agentes de união Metal Zirconia Primer/ Ivoclar Vivadent, Alloy Primer/ Kuraray Co. e RelyX Ceramic Primer/ 3M ESPE (Figura 3). Já os tratamentos de superfície avaliados foram o jateamento com óxido de alumínio 50 m (BIO-ART Equipamentos Odontológicos Ltda.) e o sistema Rocatec/ 3M ESPE (Figura 4). As marcas comerciais dos materiais empregados neste estudo e suas características são apresentadas na Tabela 1. 
TABELA 1 - Materiais comerciais empregados para avaliar a influência de tratamentos de superfície na adesão entre zircônia e sistemas para cimentação.

\begin{tabular}{|c|c|c|c|}
\hline MATERIAL & COMPOSIÇÃO & LOTE & FABRICANTE \\
\hline Rely X U100'TM & $\begin{array}{l}\text { Ésteres ácido fosfórico metacrilato, sílica, } \\
\text { dimetacrilatos, sulfonato de sódio }\end{array}$ & 318258 & 3M/ESPE \\
\hline Clearfil SE Bond & $\begin{array}{l}\text { Primer: MDP; Dimetacrilato } \\
\text { hidrófilo;Canforoquinona; HEMA; Água; } \\
\text { N,NDietanol P Toluidina } \\
\text { Adesivo: MDP; BisGMA; HEMA; Dimetacrilato; } \\
\text { N,N Dietanol P Toluidina;Canforoquinona; } \\
\text { Sílica coloidal silanizada }\end{array}$ & $379 Y$ & Kuraray Co. \\
\hline $\begin{array}{l}\text { Metal/Zirconia } \\
\text { Primer }\end{array}$ & $\begin{array}{l}\text { Mistura de dimetacrilatos, solventes, ácido } \\
\text { fosfônico, iniciador e estabilizador }\end{array}$ & J23590 & $\begin{array}{l}\text { Ivoclar } \\
\text { Vivadent }\end{array}$ \\
\hline Alloy Primer & Acetona, MDP, 6-VBATDT & $268 \mathrm{AA}$ & Kuraray Co. \\
\hline $\begin{array}{l}\text { Rely X Ceramic } \\
\text { Primer }\end{array}$ & $\begin{array}{l}\text { Silano pré-hidrolizado } \\
\text { (composição não informada) }\end{array}$ & 7YA & 3M/ESPE \\
\hline Rocatec & $\begin{array}{l}\text { Partículas de óxido de alumínio modificadas } \\
\text { por sílica } 110 \mathrm{~m}\end{array}$ & & 3M/ESPE \\
\hline $\begin{array}{c}\text { Jateamento } \\
\left(\mathrm{Al}_{2} \mathrm{O}_{3}\right)\end{array}$ & Partículas de óxido de alumínio de 50 m & & Bioart \\
\hline Ácido Fosfórico & Ácido Fosfórico 37\% & 7JK & 3M/ESPE \\
\hline Procera® Zirconia & Zircônia estabilizada com ítrio & & Nobel Biocare \\
\hline
\end{tabular}

Para a cimentação dos espécimes foi selecionado o aparelho de luz halógena (Fotopolimerizador Ultralux, Dabi Atlante, Ribeirão Preto/SP - Brasil), para a polimerização. A densidade de potência utilizada para cada técnica de fotoativação era checada antes do uso do aparelho por meio de um radiômetro, e sofreu uma variação 480 e $500 \mathrm{mw} / \mathrm{cm}^{2}$. 


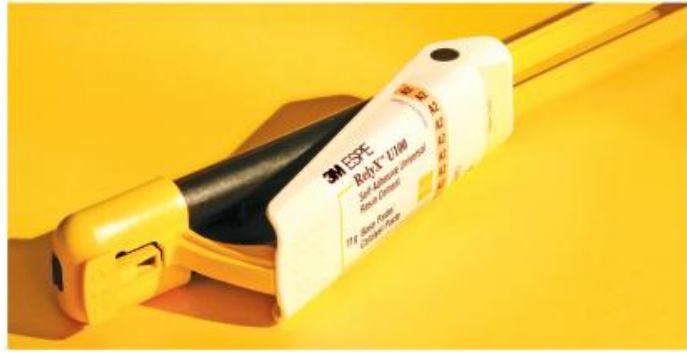

Figura 1 - Rely X U100/3M ESPE

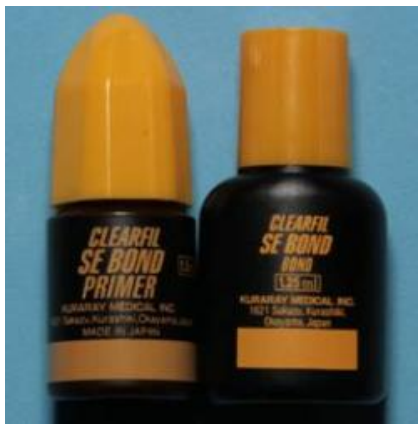

Figura 2 - Clearfil SE Bond / Kuraray Co.

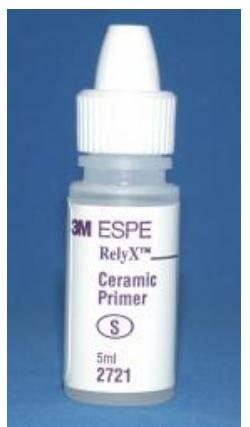

Figura 3A- RelyX Ceramic Primer / 3M ESPE

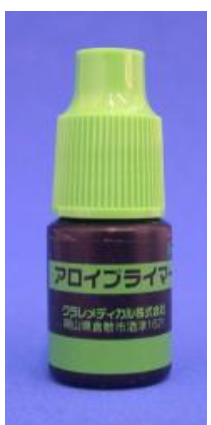

Figura 3B - Alloy Primer / Kuraray Co.

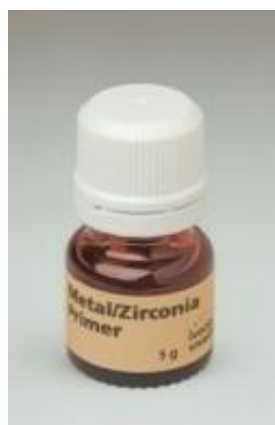

Figura 3C-Metal/Zirconia Primer / Ivoclar

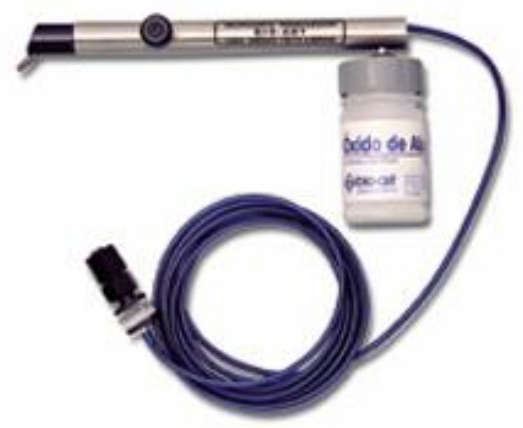

Figura 4A-Aparelho de Jateamento $\left(\mathrm{Al}_{2} \mathrm{O}_{3}\right)$ BIO-ART

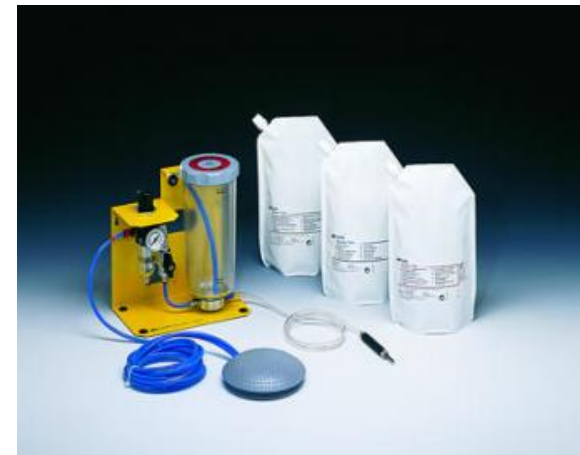

Figura 4B- Sistema Rocatec 3M/ESPE 


\subsection{MÉTODOS}

\subsubsection{Delineamento Experimental}

Este estudo in vitro envolveu a confecção de espécimes com cilindros de PROCERA ${ }^{\circledR}$ AllZircon que foram submetidos ao teste de cisalhamento por meio de uma alça de fio ortodôntico. Foi avaliada a resistência adesiva de um cimento resinoso auto-adesivo de presa dual aos cilindros de zircônia. Diferentes condições de superfície da zircônia em função de alguns agentes de união foram analisadas, totalizando 12 grupos experimentais com 10 cilindros de zircônia em cada. Os grupos foram formados da seguinte forma:

\begin{tabular}{|c|c|c|c|c|}
\hline GRUPOS & CERÂMICA & CIMENTO & AGENTE DE UNIÃO & $\begin{array}{c}\text { TRATAMENTO DE } \\
\text { SUPERFÍCIE }\end{array}$ \\
\hline Co & ProceraAll-Zircon & $\begin{array}{l}\text { RelyX'M } \\
\text { U100 }\end{array}$ & Nenhum & Ácido fosfórico 37\% \\
\hline CoJat & ProceraAll-Zircon & $\begin{array}{c}\text { RelyX'TM } \\
\text { U100 }\end{array}$ & Nenhum & Jateamento $\left(\mathrm{AL}_{2} \mathrm{O}_{3}\right)$ \\
\hline CoRoc & ProceraAll-Zircon & $\begin{array}{l}\text { RelyX'M } \\
\text { U100 }\end{array}$ & Nenhum & Jateamento (Rocatec) \\
\hline Ap & ProceraAll-Zircon & $\begin{array}{l}\text { RelyX'M } \\
\text { U100 }\end{array}$ & Alloy Primer & Ácido fosfórico 37\% \\
\hline ApJat & ProceraAll-Zircon & $\begin{array}{l}\text { RelyX'M } \\
\text { U100 }\end{array}$ & Alloy Primer & Jateamento $\left(\mathrm{AL}_{2} \mathrm{O}_{3}\right)$ \\
\hline ApRoc & ProceraAll-Zircon & $\begin{array}{l}\text { RelyX'M } \\
\text { U100 }\end{array}$ & Alloy Primer & Jateamento (Rocatec) \\
\hline $\mathrm{Cb}$ & ProceraAll-Zircon & $\begin{array}{l}\text { RelyX'M } \\
\text { U100 }\end{array}$ & Metal Primer Zircônia & Ácido fosfórico 37\% \\
\hline CbJat & ProceraAll-Zircon & $\begin{array}{l}\text { RelyX'M } \\
\text { U100 }\end{array}$ & Metal Primer Zircônia & Jateamento $\left(\mathrm{AL}_{2} \mathrm{O}_{3}\right)$ \\
\hline CbRoc & ProceraAll-Zircon & $\begin{array}{l}\text { RelyXTM } \\
\text { U100 }\end{array}$ & Metal Primer Zircônia & Jateamento (Rocatec) \\
\hline Mzp & ProceraAll-Zircon & $\begin{array}{l}\text { RelyX'M } \\
\text { U100 }\end{array}$ & Clearfill SE Bond & Ácido fosfórico 37\% \\
\hline MzpJat & ProceraAll-Zircon & $\begin{array}{l}\text { RelyX'M } \\
\text { U100 }\end{array}$ & Clearfill SE Bond & Jateamento $\left(\mathrm{AL}_{2} \mathrm{O}_{3}\right)$ \\
\hline MzpRoc & ProceraAll-Zircon & $\begin{array}{l}\text { RelyX'M } \\
\text { U100 }\end{array}$ & Clearfill SE Bond & Jateamento (Rocatec) \\
\hline
\end{tabular}

\subsubsection{Dispositivos para confecção dos espécimes}

Para o preparo dos espécimes, os cilindros de zircônia foram presos em um dispositivo metálico para a aplicação do cimento resinoso. 
O dispositivo metálico é composto de uma base, um braço e um platô, onde se acopla uma matriz dividida de teflon (politetrafluoretano) fixada através de um parafuso lateral (Figura 4.). O dispositivo possui um orifício central com $3,5 \mathrm{~mm}$ de diâmetro e 3,0 mm de altura e dois pinos metálicos com uma única forma de encaixe (Figura 4.2). O cimento resinoso era aplicado após a fixação do cilindro de zircônia no dispositivo metálico, estando encaixado na matriz de teflon.

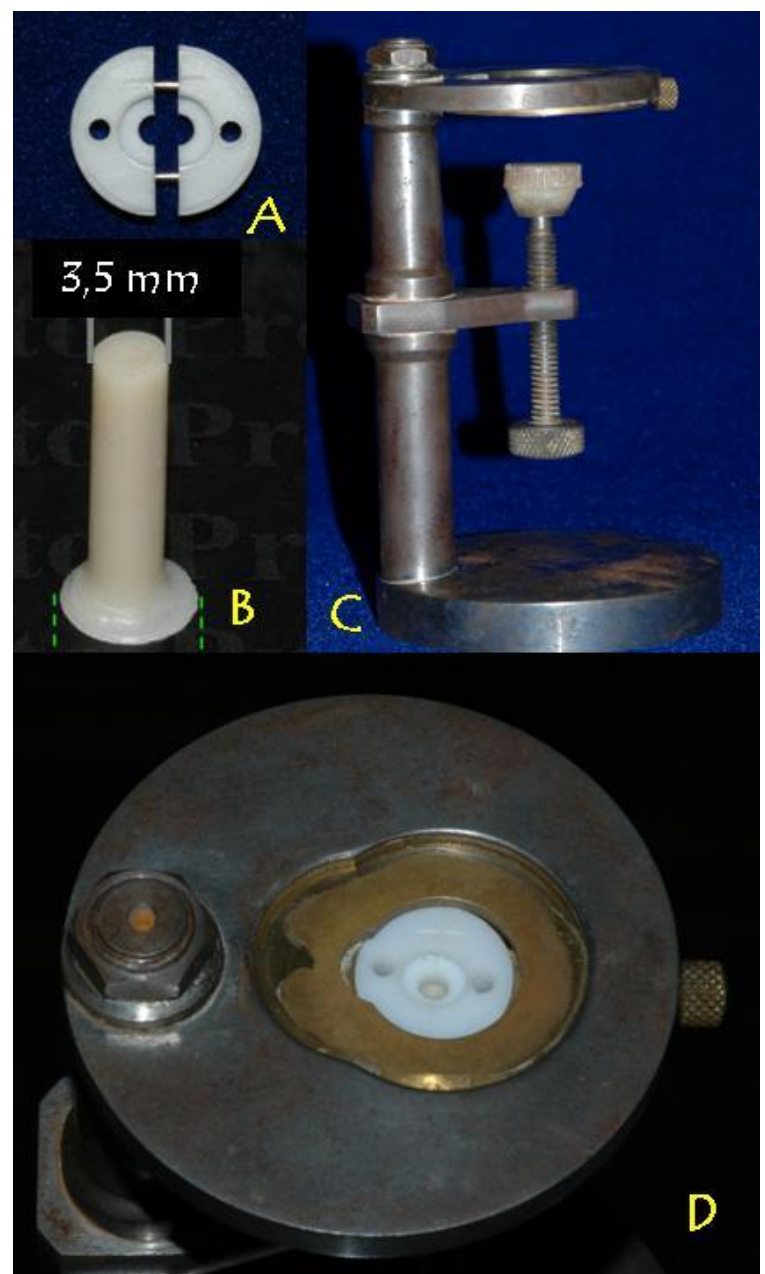

Figura 5- Dispositivos: (A)- matriz de teflon dividida em duas partes; (B)- infraestrutura de zircônia; (C)- dispositivo metálico utilizado para manter os cilindros de porcelana e a matriz de teflon; (D) - matriz de teflon ajustada ao dispositivo metálico.

\subsubsection{Procedimentos Prévios}


Os cilindros foram planificados com lixa de silicone carbide de granulação 320 e polidos com as lixas de granulações 400, 600 e 1200 sob irrigação e pressão manual em uma Politriz Metalográfica (APL4, Arotec), com o objetivo de promover polimento padrão na superfície.

Após a planificação e polimento, os cilindros eram levados ao aparelho de ultra-som T14 (L\&R ultrasonic) por 3 minutos em água deionizada.

Na seqüência, os cilindros eram limpos com ácido fosfórico a 37\% por um total de 20s, lavados pelo dobro do tempo (40s) e secos com jato de ar, como meio de limpeza da superfície (SADAN, BLATZ, LANG, 2005). Então eram separados aleatoriamente, de acordo com os grupos experimentais.

\subsubsection{Preparo dos Espécimes}

Os cilindros de zircônia foram divididos de acordo com o tratamento superficial e agente de união empregados, nos seguintes grupos:

- Grupo controle (Co): nenhum tratamento na superfície foi feito após a limpeza com ácido.

- Grupo CoJat: após a limpeza, foi submetido ao jateamento com partículas de óxido de alumínio de $50 \mu \mathrm{m}$, o tratamento foi realizado durante15s a uma distância de $10 \mathrm{~mm}$ da superfície através do aparelho (micretcher da Bioart). Em seguida, os cilindros eram levados ao aparelho de ultra-som por 3 minutos em álcool 96\% (ATSU; KILICARSLAN; KUCUKESMEN; AKA, 2006).

- Grupos CoRoc: após a limpeza, foi submetido ao tratamento com Rocatec, que é realizado em 3 etapas, $1^{\circ}$ - jateamento com partículas de $\mathrm{Al}_{2} \mathrm{O}_{3}$ (Rocatec-Pre powder), por 10 segundos, a uma distância de $10 \mathrm{~mm}$ da superfície, com uma pressão de 2,8 bar; $2^{\circ}$ - jateamento com partículas especiais de sílica (Rocatec-Plus powder), por 13 segundos, a uma distância de $10 \mathrm{~mm}$ da superfície, com uma pressão de 2,8 bar; $3^{\circ}$ - silanização com Rocatec-Sil, ou seja, o silano foi aplicado sobre a superfície e seco, e então foi aplicado o cimento.

- Grupo Ap: após a limpeza foi aplicado o primer Alloy Primer, e em seguida um jato de ar por 10 segundos, aguardando a superfície secar, para então ser aplicado o cimento. 
- Grupo ApJat: o mesmo protocolo descrito para o grupo CoJat e em seguido e descrito no grupo Ap.

- Grupo ApRoc: o mesmo protocolo descrito para o grupo CoRoc e em seguido e descrito no grupo Ap.

- Grupo Cb: após a limpeza foi aplicado o primer, e depois de 20 segundos, um jato de ar por mais $10 \mathrm{~s}$, para auxiliar na evaporação do solvente, em seguida foi aplicado o adesivo, seguido de um jato de ar por $10 \mathrm{~s}$ e fotopolimerizado por $10 \mathrm{~s}$, para então ser aplicado o cimento.

- Grupo CbJat: o mesmo protocolo descrito para o grupo CoJat e, em seguida, o descrito no grupo $\mathrm{Cb}$.

- Grupo CbRoc: o mesmo protocolo descrito para o grupo CoRoc e, em seguida, o descrito no grupo $\mathrm{Cb}$.

- Grupo Mzp: após a limpeza foi aplicado o primer Metal/ Zircônia Primer, e depois de 180 segundos foi aplicado o cimento.

- Grupo MzpJat: o mesmo protocolo descrito para o grupo CoJat e, em seguida, o descrito no grupo Mzp.

- Grupo MzpRoc: o mesmo protocolo descrito para o grupo CoRoc e, em seguida, o descrito no grupo Mzp.

$\mathrm{Na}$ seqüência, os cilindros eram fixados no dispositivo metálico para a realização da cimentação (Figura 6A). O cimento era inserido e acomodado na matriz com o auxílio de uma espátula para resina (Hu-Friedy, mini 1, USA) e os excessos removidos (Figura 6B e 6C). A cimentação foi feita de acordo com as orientações do fabricante. O cimento era espatulado por 20 s e levado para a matriz de teflon, com 2 minutos ele era fotoativado e aguardava-se o tempo total de presa, 5 minutos, para a remoção do espécime do dispositivo (Figura $6 \mathrm{D})$.

Após a sua confecção, os espécimes eram mantidos imersos em água deionizada por 24 horas em estufa a $37^{\circ} \mathrm{C}$.

\subsubsection{Teste de Resistência ao Cisalhamento}

Para a adaptação dos espécimes ao dispositivo de cisalhamento, uma matriz de teflon foi confeccionada, com $12 \mathrm{~mm}$ de altura, aproximadamente, e 
uma perfuração cilíndrico-circular de $3,5 \mathrm{~mm}$ de diâmetro no centro, com a finalidade de melhorar a adaptação dos corpos-de-prova no dispositivo de cisalhamento (Figura 7).

Os testes de resistência ao cisalhamento foram realizados de forma padronizada em uma máquina de ensaios universal (Emic-2000) à velocidade constante de $0,5 \mathrm{~mm} /$ minuto. Os espécimes eram levados a máquina de ensaio, já adaptados à matriz de teflon (Figura 7B e 7C), onde por meio de um fio de aço contornando o cilindro, próximo à interface, foi aplicada a força necessária para o rompimento da união entre o cimento e a zircônia (Figura 8).

\subsection{CONVERSÃO DE VALORES}

A carga necessária para provocar o início da fratura foi registrada em quilograma/força (Kgf) e foi então convertida para MegaPascal (MPa) . A resistência de união ao cisalhamento em MPa foi calculada pela seguinte fórmula:

$$
\mathrm{Rc}=\mathrm{F} / \mathrm{A} \quad \mathrm{A}=\pi \mathrm{r}^{2}
$$

onde: Rc é, a resistência ao cisalhamento; $F(\mathrm{KgF})$, a força aplicada; e A ( $\left.\mathrm{mm}^{2}\right)$, a área de união. 


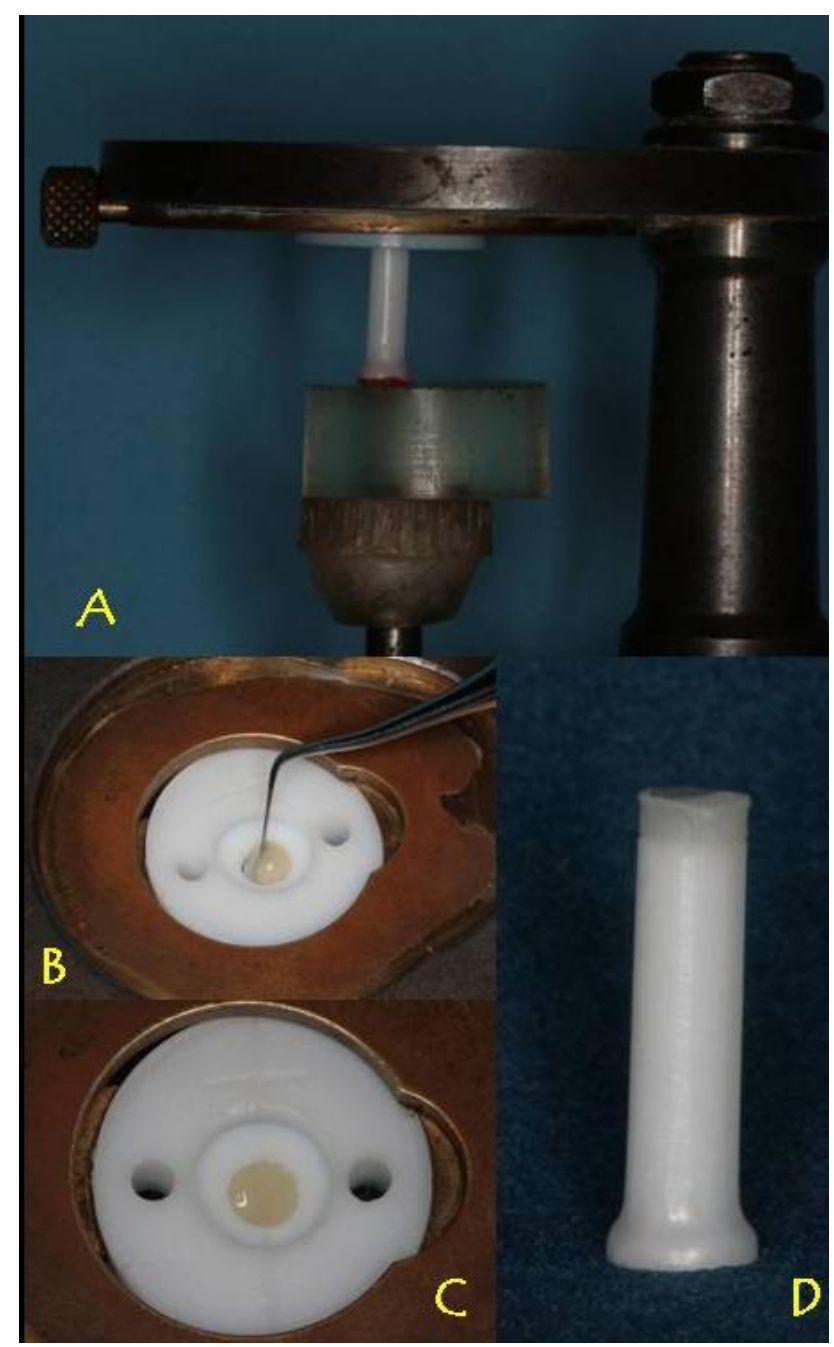

Figura 6- Confecção espécimes: (A)- cilindro em posição; (B)- inserção cimento com espátula Hu-Fridy; (C)- matriz preenchida; (D)- espécime pronto.

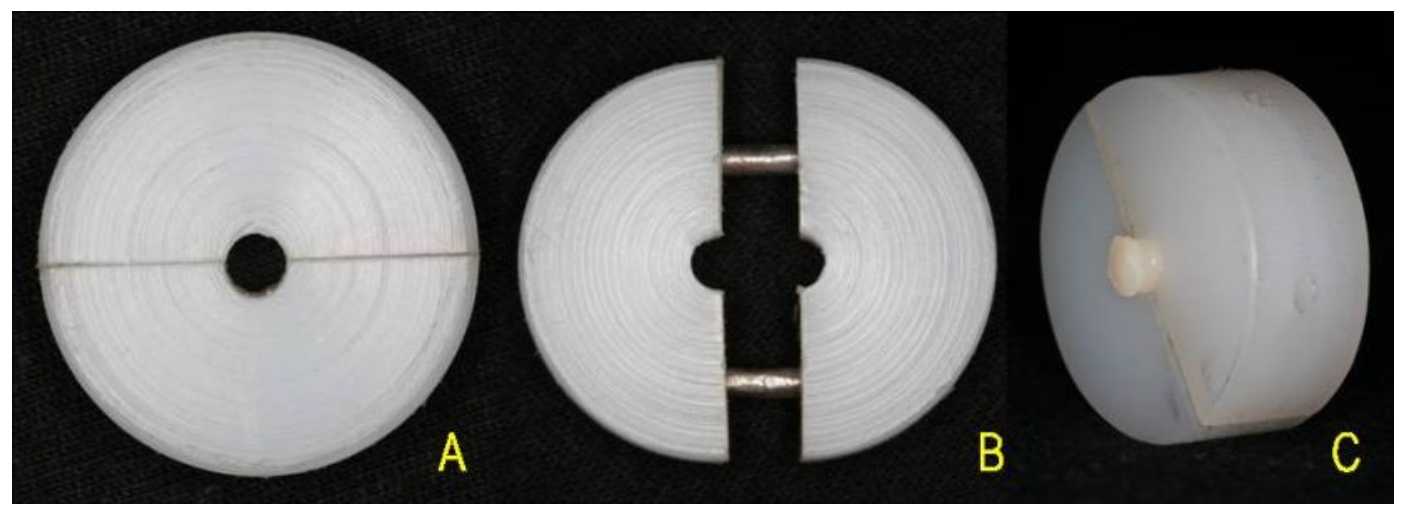

Figura 7- Matriz: (A)- Matriz de teflon; (B)- Matriz aberta para adaptação do espécime; (C)Espécime adaptado na matriz para o ensaio mecânico. 


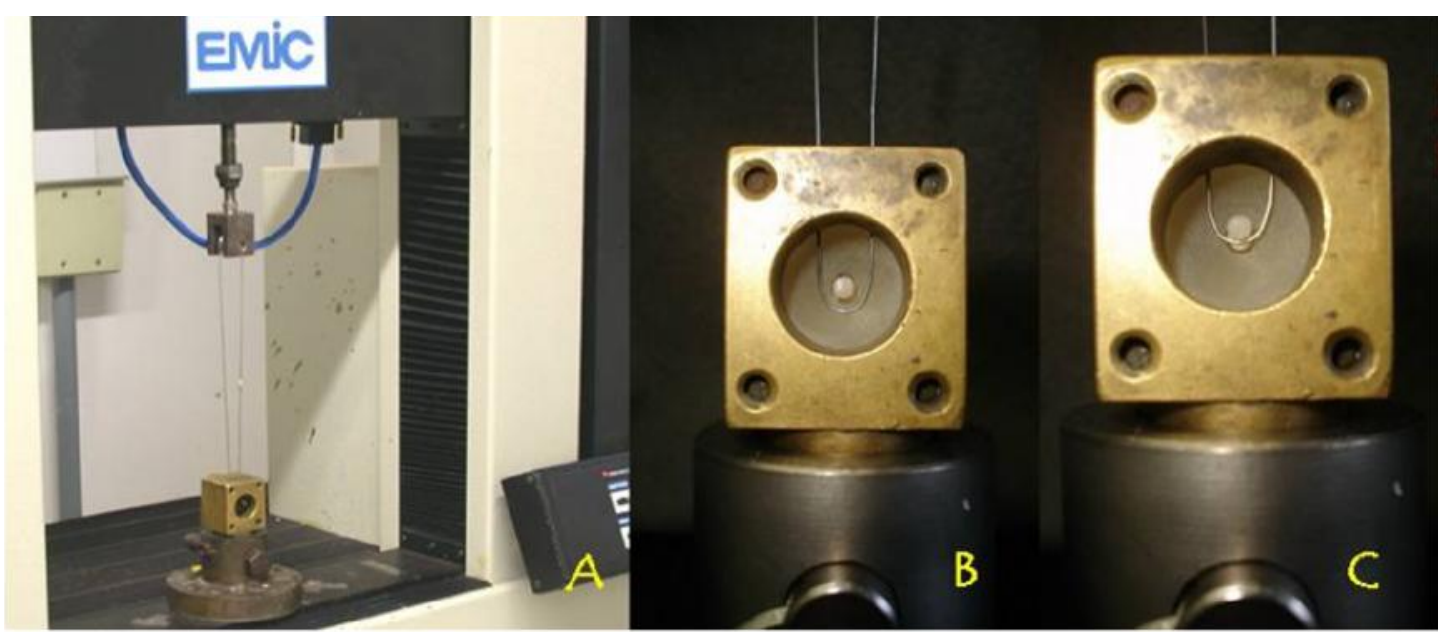

Figura 8- Ensaio mecânico: (A)- maquina de ensaio universal EMIC; (B)- espécime em posição, com a alça de fio ortodôntico posicionada para o tracionamento;(C)- momento de ruptura do espécime.

\subsection{ANÁLISE ESTATÍSTICA}

Os resultados foram submetidos à análise estatística para a verificação de diferenças ou não entre os grupos, levando em consideração os valores de resistência de união, independente do tratamento realizado (tratamentos de superfície e sistemas de união). Foi aplicada a análise de variância a um critério (ANOVA) e após esta avaliação, os dados foram submetidos ao teste de Tukey para comparações individuais entre os diferentes grupos, com nível de significância de 5\%. O programa estatístico utilizado foi o SAS System 6.11 software (SPSS Inc., Tulsa/OK - USA). 


\section{RESULTADOS}
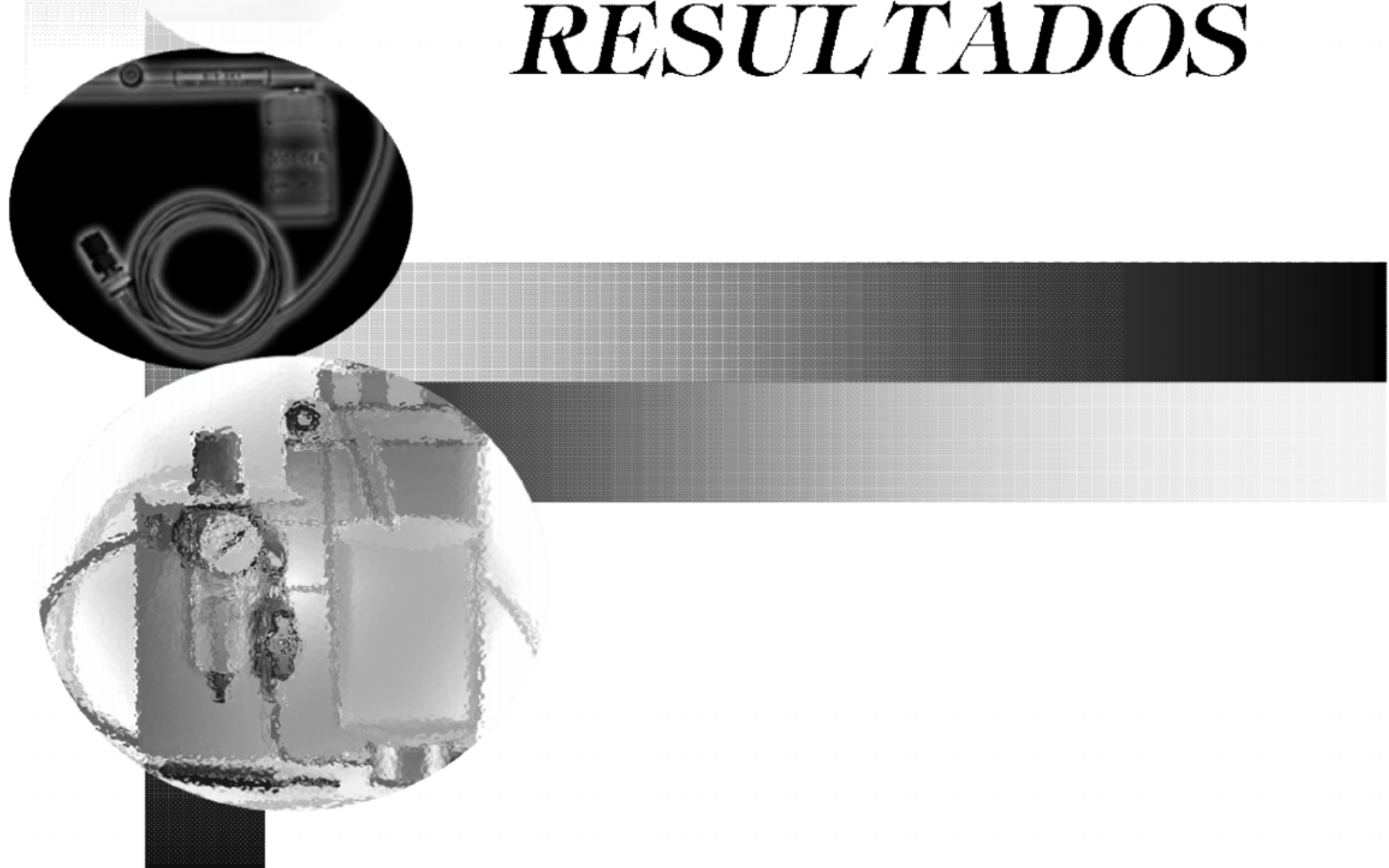


\section{RESULTADOS}

Os dados obtidos no ensaio de resistência ao cisalhamento (Anexo 1) foram submetidos à Análise de Variância a um critério (resistência de união) e posteriormente ao teste de Tukey, em nível de significância de 5\%.

Para facilitar a compreensão dos resultados, foi feita uma comparação entre os diferentes grupos e outra comparação levando em consideração os diferentes tratamentos superficiais, mecânicos (jateamento com óxido de alumínio e jateamento com sílica) ou químicos (aplicação do sistema adesivo Clearfil SE Bond, e dos primers Metal Zircônia Primer e Alloy Primer), aplicados na superfície da infra-estrutura de zircônia, separadamente.

A tabela 1 e a figura 1 mostram as médias de resistência adesiva os desvios-padrão obtidos para os diferentes sistemas de união, independente do tratamento mecânico realizado na superfície da infra-estrutura de zircônia.

Tabela 1 - Valores médios e desvios-padrão da resistência ao cisalhamento (MPa) na união infra-estrutura de zircônia / tratamento da superfície com agentes de união, independente do tratamento superficial mecânico.

\begin{tabular}{cccc}
\hline Agentes de união & Média (MPa) & Desvio Padrão & N \\
\hline Controle (U100) & $6,75^{\mathrm{a}}$ & 4,58 & 30 \\
Alloy Primer & $10,01^{\mathrm{a}, \mathrm{c}}$ & 5,60 & 30 \\
Clearfill SE Bond & $17,07^{\mathrm{b}}$ & 5,74 & 30 \\
Metal Zircônia Primer & $11,26^{\mathrm{c}}$ & 5,88 & 30 \\
\hline$p=0,044187$ & & \\
\hline Letras diferentes, numa mesma coluna, indicam diferença estatisticamente significante. &
\end{tabular}

A comparação entre os diferentes materiais testados através do Teste de Variação Múltipla de Tukey evidenciou que o sistema adesivo Clearfill SE Bond teve um comportamento estatisticamente superior aos demais materiais. Entre os primers, o Metal Zircônia Primer apresentou maior valor de resistência de união que o Alloy Primer, mas sem diferença estatística significativa, mesmo que estatisticamente superior ao grupo controle. O Alloy Primer mostrou valores próximos aos do grupo controle, não havendo diferença estatísticamente significante. 


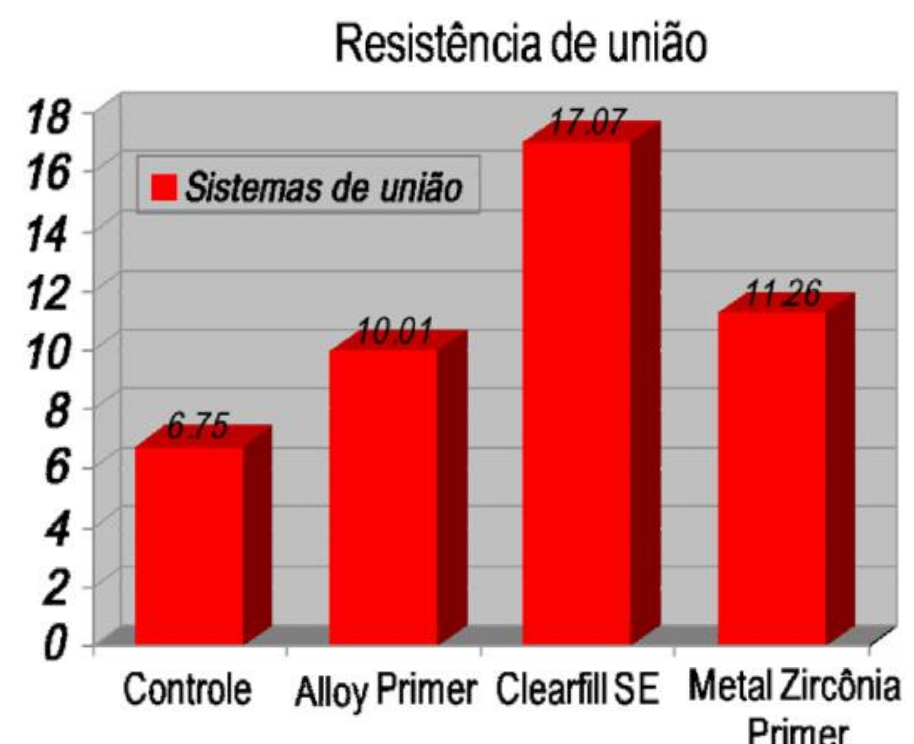

Gráfico 1 - Valores médios da resistência ao cisalhamento (MPa) na união infraestrutura de zircônia / tratamento da superfície com agentes de união.

A tabela 2 e a figura 2 evidenciam os valores médios e os desviospadrão obtidos pelos diferentes tratamentos realizados na superfície da infraestrutura, não levando em consideração os sistemas de união empregados.

Tabela 2 - Valores médios e desvios-padrão da resistência ao cisalhamento (MPa) na união infra-estrutura de zircônia / tratamento mecânico da superfície, independente dos agentes de união aplicados.

\begin{tabular}{cccc}
\hline Tratamento de superfície & Média (MPa) & Desvio Padrão & $\mathbf{N}$ \\
\hline Controle & $6,56^{\mathrm{a}}$ & 3,94 & 40 \\
Jateamento com óxido de alumínio & $11,93^{\mathrm{b}}$ & 6,27 & 40 \\
Rocatec & $15,33^{\mathrm{c}}$ & 5,56 & 40 \\
\hline$p=0,015995$ & &
\end{tabular}

Letras diferentes, numa mesma coluna, indicam diferença estatisticamente significante.

Letras iguais, numa mesma coluna, indicam semelhança estatística.

Quando a resistência ao cisalhamento da união infra-estrutura de zircônia/ tratamentos superficiais foi comparada, os resultados mostraram que houve diferença estatística significante entre todos os grupos, sendo que o revestimento da superfície com partículas de sílica de 110 $\mu$ m (Sistema Rocatec) proporcionou os maiores valores de união, seguido do jateamento 
com óxido de alumínio $50 \mu \mathrm{m}$ e por último o grupo controle, que não recebeu nenhum tratamento.

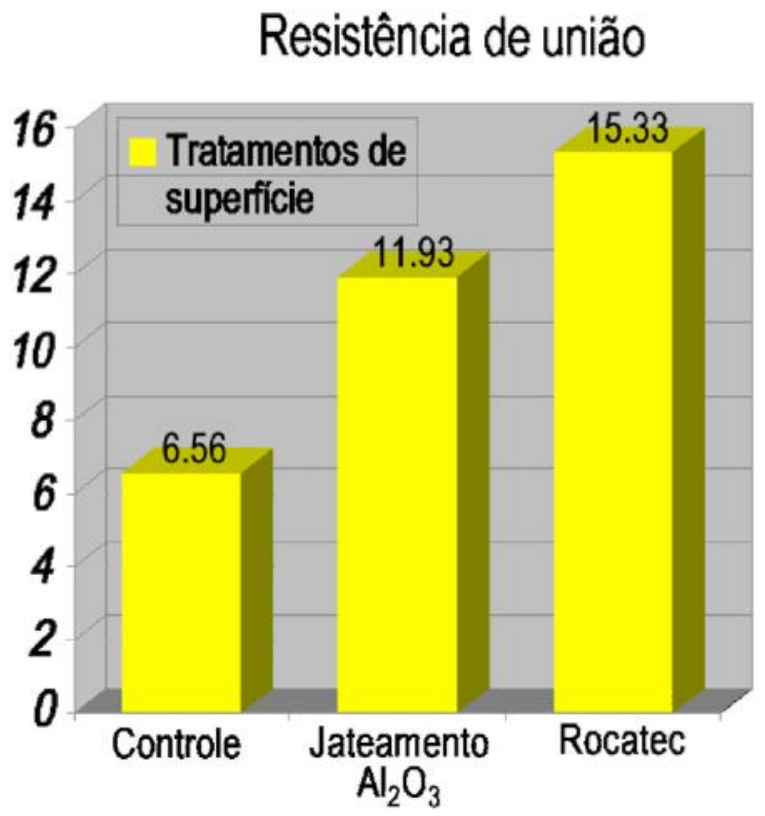

Gráfico 2 - Valores médios da resistência ao cisalhamento (MPa) na união infraestrutura de zircônia / tratamento mecânico da superfície.

A tabela 3 e a figura 3 indicam as médias e os desvios-padrão dos grupos avaliados, levando em consideração todos os tratamentos superficiais recebidos.

Tabela 3 - Valores médios e desvios-padrão (MPa) na associação dos tratamentos avaliados, tratamento mecânico da superfície e sistema de união.

\begin{tabular}{cccc}
\hline Grupos & Média (MPa) & Desvio Padrão & $\mathbf{N}$ \\
\hline Co & $3,58^{\mathrm{a}}$ & 1,14 & 10 \\
CoJat & $5,93^{\mathrm{a}, \mathrm{c}}$ & 1,67 & 10 \\
CoRoc & $11,85^{\mathrm{b}, \mathrm{f}}$ & 4,92 & 10 \\
Ap & $4,87^{\mathrm{a}, \mathrm{c}}$ & 2,01 & 10 \\
ApJat & $10,07^{\mathrm{b}, \mathrm{c}}$ & 2,26 & 10 \\
ApRoc & $14,47^{\mathrm{b}, \mathrm{e}}$ & 6,03 & 10 \\
Cb & $11,80^{\mathrm{b}}$ & 2,93 & 10 \\
CbJat & $20,58^{\mathrm{d}}$ & 4,61 & 10 \\
CbRoc & $17,79^{\mathrm{d}, \mathrm{e}}$ & 5,22 & 10 \\
Mzp & $5,51^{\mathrm{a}, \mathrm{c}}$ & 2,34 & 10 \\
MzpJat & $10,28^{\mathrm{b}, \mathrm{c}}$ & 1,82 & 10 \\
MzpRoc & $17,30^{\mathrm{d}, \mathrm{e}, \mathrm{f}}$ & 4,48 & \\
\hline$p=0,000001$ & &
\end{tabular}


Onde: $\mathrm{Co}=$ nenhum tratamento; CoJat $=$ Jateamento $\mathrm{Al}_{2} \mathrm{O}_{3} ;$ CoRoc $=$ Rocatec; $\mathrm{Ap}=$ Alloy primer; ApJat $=$ Alloy primer + Jateamento $\mathrm{Al}_{2} \mathrm{O}_{3} ; \mathrm{ApRoc}=$ Alloy primer + Rocatec $; \mathrm{Cb}=$ Clearfill $\mathrm{SE}$ Bond; CbJat = Clearfill SE Bond + Jateamento $\mathrm{Al}_{2} \mathrm{O}_{3}$. CbRoc = Clearfill SE Bond + Rocatec; $\mathrm{Mzp}=$ Metal Zircônia Primer; MzpJat = Metal Zircônia Primer + Jateamento $\mathrm{Al}_{2} \mathrm{O}_{3} ; \mathrm{MzpRoc}=$ Metal Zircônia Primer + Rocatec.

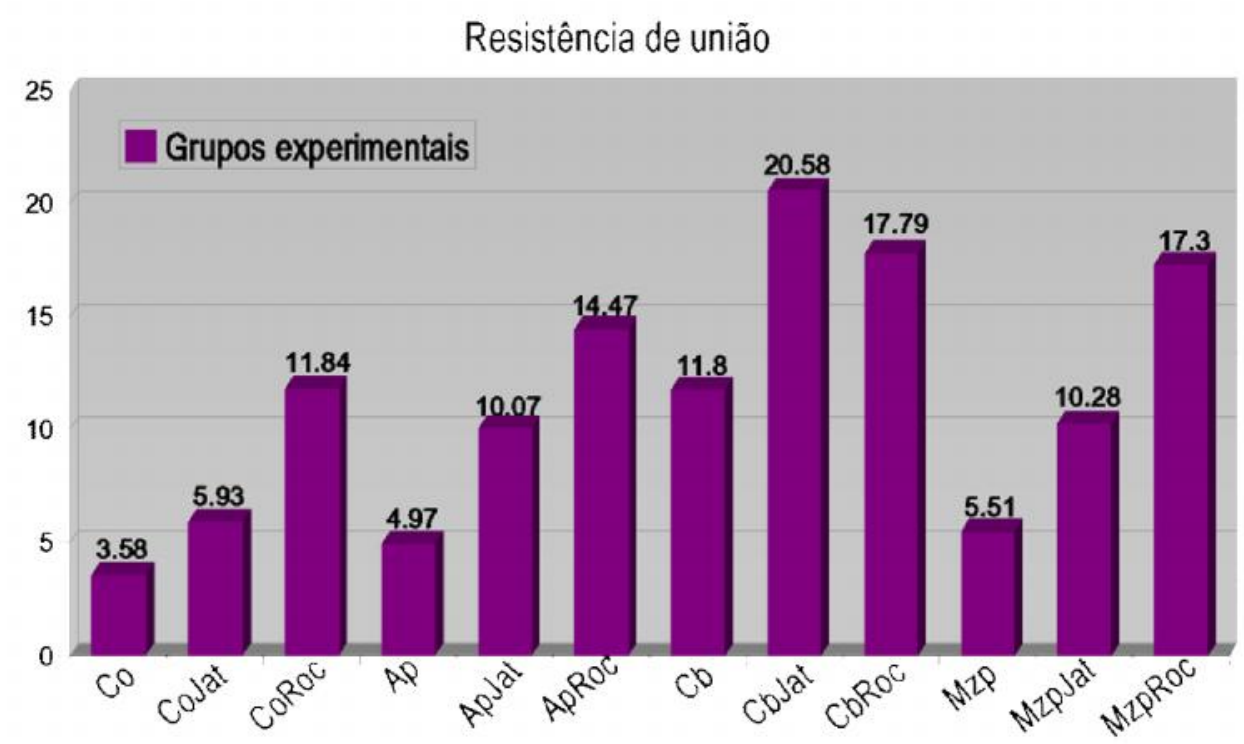

Gráfico 3 - Valores médios da resistência ao cisalhamento (MPa) à união infraestrutura de zircônia dos diferentes grupos experimentais.

A análise de variância mostrou que a associação do sistema adesivo Clearfill SE Bond com o jateamento $\mathrm{Al}_{2} \mathrm{O}_{3}$ (CbJat) resultou em uma resistência de união significativamente superior aos demais grupos, exceto para os grupos que associaram o sistema Rocatec com o adesivo Clearfill SE Bond (CbRoc) e com o primer Metal Zircônia Primer (MzpRoc), em que não houve diferença significante entre eles. Já o menor valor foi encontrado no grupo que não recebeu nenhum tratamento prévio a aplicação do agente cimentante autoadesivo (controle). Os primers metálicos, Metal Zircônia Primer e Alloy Primer apresentaram valores intermediários, sendo que após a realização dos tratamentos superficiais houve uma melhora significativa para ambos os materiais.

Os diferentes tratamentos dados à superfície da zircônia foram efetivos. O tratamento da superfície com o sistema Rocatec aumentou os valores de união para todos os materiais, exceto para o sistema adesivo Clearfill SE Bond, embora essa diferença não tenha sido significativa quando comparado ao jateamento com $\mathrm{Al}_{2} \mathrm{O}_{3}$. A diferença entre os dois tratamentos foi significante 
apenas para o primer Metal Zircônia Primer (MzpJat e MzpRoc) e para os grupos que não receberam nenhum sistema de união (CoJat e CoRoc).

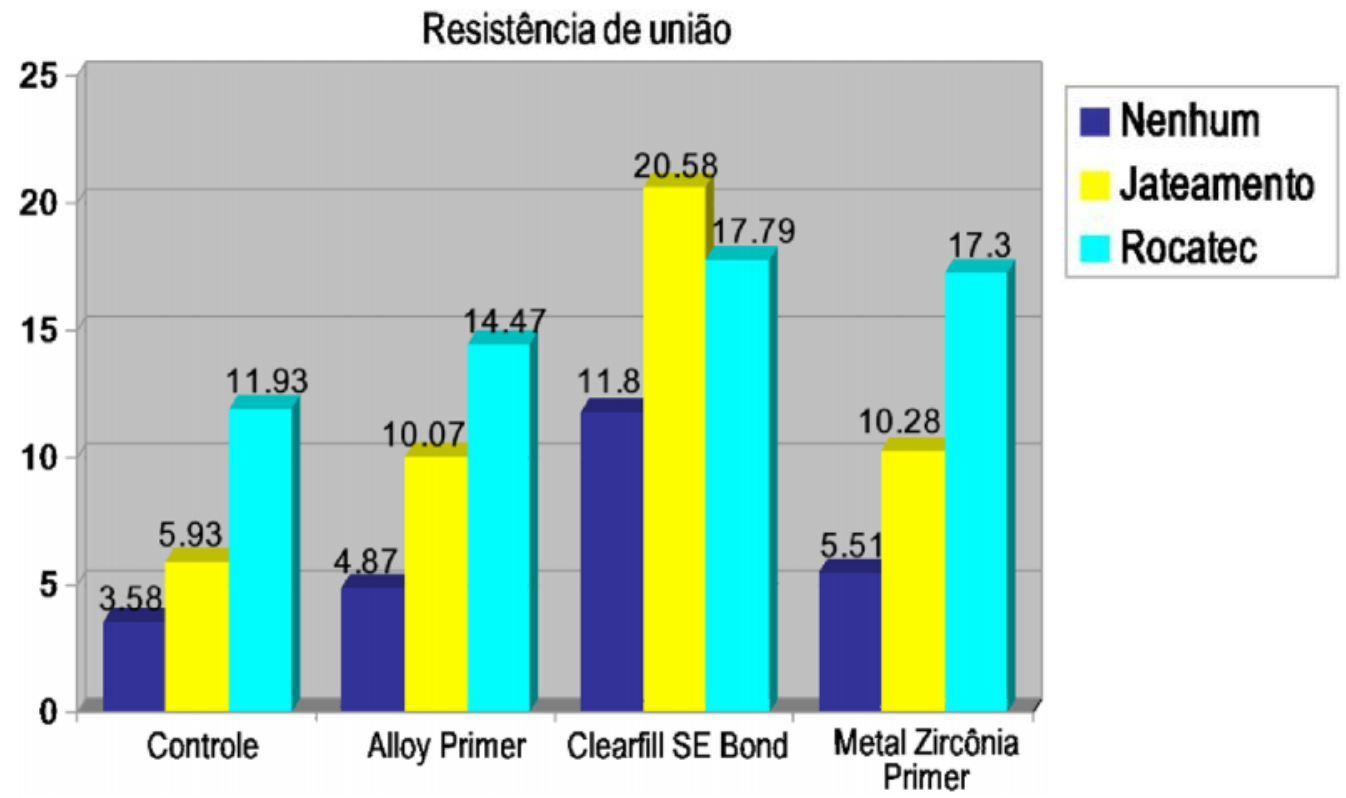

Gráfico 4 - Valores médios da resistência ao cisalhamento (MPa) à infra-estrutura de zircônia, mostrando a associação dos diferentes tratamentos realizados.

Os padrões de fratura dos espécimes testados foram predominantemente do tipo adesiva, entre a cerâmica e o cimento. Apenas 3 espécimes dos grupos nos quais foi utilizado o sistema adesivo Clearfill SE Bond apresentaram falhas do tipo mista. 


\section{DISCUSSÃO}




\section{DISCUSSÃO}

\subsection{Da justificativa e proposição}

O desenvolvimento de tecnologias para a produção de novos materiais biocompatíveis tem sido motivado pela demanda de materiais que executem novas funções ou desempenhem antigas funções de forma mais adequada. (HENCH, 1998). Hoje as cerâmicas constituem uma das principais alternativas para a reconstrução das estruturas dentárias perdidas, já que se tratam do material que melhor reproduz as propriedades ópticas do esmalte e da dentina, como fluorescência, opalescência e translucidez (VAN NOORT, 2004). Embora as cerâmicas possuam excelentes propriedades físicas, são materiais friáveis que, frente aos esforços, podem fraturar-se devido à propagação de defeitos microscópicos presentes na superfície (McLEAN, 1991). Essa busca pelo aperfeiçoamento estético associada à necessidade em se obter boas propriedades mecânicas, levaram à eliminação das infra-estruturas metálicas, surgindo assim os sistemas cerâmicos reforçados.

As cerâmicas de elevado conteúdo cristalino, como alumina e zircônia, possuem propriedades mecânicas superiores às das cerâmicas convencionais, e são empregadas como material para a confecção de infra-estruturas. O uso da alumina, entretanto, tem sido questionado devido à possibilidade de propagação de trincas entre os cristais, o que reduz sua resistência à fadiga e faz com que este material seja considerado uma cerâmica de resistência intermediária (ZHANG; PAJARES; LAWN, 2004a). Por outro lado, o dióxido de zircônia $\left(\mathrm{ZrO}_{2}\right)$, uma cerâmica de alta resistência, tem sido sugerido como material de eleição para substituir a alumina, por ser um material biocompatível, por apresentar propriedades mecânicas superiores e boas propriedades estéticas. (PICONI \& MACCAURO, 1999; ZHANG; PAJARES; LAWN, 2004a).

O sistema In-Ceram apresenta resistência à tração de 3 a 4 vezes maior quando comparado às cerâmicas convencionais. Este sistema apresenta três 
variáveis, de acordo com o seu principal componente: alumina $\left(\mathrm{Al}_{2} \mathrm{O}_{3}\right)$ - InCeram Alumina, spinel $\left(\mathrm{MgAl}_{2} \mathrm{O}_{4}\right)$ - In-Ceram Spinel e o zircônia $\left(\mathrm{Al}_{2} \mathrm{O}_{3} \mathrm{ZrO}_{2}\right)$ In-Ceram Zircônia. O sistema In-Ceram Zircônia proporciona uma maior resistência à tração, em torno de $476 \mathrm{MPa}$ e resistência à fratura em torno de 4.9 MPa/m ${ }^{1 / 2}$ (GUAZZATO; ALBAKRY; RINGER; SWAIN, 2004b). Já o sistema IPS Empress apresenta resistência à tração de $106 \mathrm{MPa}$ enquanto o IPS Empress 2 de 306 MPa (GUAZZATO; ALBAKRY; RINGER; SWAIN, 2004). Esse sistema é indicado para a confecção de coroas de cerâmica puras unitárias anterior e posterior, inlays, onlays, facetas e, mais recentemente, a utilização do sistema IPS Empress II para a confecção de próteses parciais fixas de 3 elementos para dente anterior até segundo pré-molar. Quanto ao sistema Procera AllCeram é composto por alto conteúdo de alumina pura (99,9\% de $\left.\mathrm{Al}_{2} \mathrm{O}_{3}\right)$, densamente sinterizada, utilizando tecnologia CAD/CAM. Apresenta excelente biocompatibilidade, resistência à flexão em torno de 687 $\mathrm{MPa}$ e resistência à fratura entre $4,48 \mathrm{MPa} / \mathrm{m}^{1 / 2}$ (WAGNER; CHU,1996). Quanto à longevidade do tratamento, foi verificada uma sobrevivência de aproximadamente $97 \%$ dos casos de restaurações utilizando o sistema Procera AllCeram, tanto para a região anterior como para a posterior, num período de 5 anos (ODEN; ANDERSSON; KRYSTEK-ONDRACEK; MAGNUSSON, 1998).

A Y-TZP apresenta resistência à flexão maior em relação aos demais sistemas cerâmicos, de $820 \mathrm{MPa}$, e resistência à fratura maior que 2000N. Os materiais de Y-TZP também exibem resistência que é quase duas vezes o valor obtido para materiais à base de alumina e pelo menos três vezes o valor demonstrado pela cerâmica de dissilicato de lítio (TINSCHERT; NATT; MAUTSCH; SPIEKERMANN; ANUSAVICE, 2001). Estas propriedades são superiores às exibidas por outra cerâmica de alta resistência (GUAZZATO; ALBAKRY; SWAIN; RINGER, 2004b).

Os elevados valores de resistência à flexão e tenacidade à fratura das cerâmicas Y-TZP devem-se principalmente à atuação do mecanismo de tenacificação por transformação martensítica da fase tetragonal para monoclínica induzida pelo campo de tensão na ponta da trinca (HANNINK; KELLY; MUDDLE, 2000). Garvie; Hannink e Pascoe (1975) foram os primeiros a mostrar como usar o potencial da zircônia com o intuito de aumentar a resistência mecânica e dureza das cerâmicas. O aumento de volume e o 
cisalhamento promovido pela transformação martensítica tendem a contrapor a abertura da trinca e, por esta razão, agem para aumentar a resistência da cerâmica à propagação da trinca. Esse aumento na resistência ocorre porque a energia associada à propagação da trinca se dissipa na transformação tetragonal-monoclínica com a expansão do volume.

A zircônia estabilizada por ítrio (Y-TZP) não possui fase vítrea devido à sua microestrutura policristalina, o que evita o fenômeno de degradação pela saliva e conseqüente aumento da propagação de trincas (ZHANG; PAJARES; LAWN, 2004a). No entanto, essa estrutura com elevado conteúdo cristalino sem fase vítrea é responsável por seu baixo potencial adesivo. Considerando que o condicionamento com ácido fluorídrico dissolve a fase vítrea da cerâmica, quando esta fase é ausente, a cerâmica se torna ácido-resistente, ou seja, nenhum tipo de ácido produz retenção micromecânica suficiente para o procedimento de união (DERAND \& DERAND, 2000; ÖZCAN \& VALLITTU, 2003).

As técnicas de adesão e os sistemas cerâmicos modernos oferecem várias opções de tratamento. A união à cerâmica tradicional a base de sílica é um procedimento previsível, que rende bons resultados quando determinadas diretrizes são seguidas. Entretanto, a composição e as propriedades físicas dos materiais cerâmicos de alta resistência, tais como as cerâmicas a base de óxido de alumínio $\left(\mathrm{Al}_{2} \mathrm{O}_{3}\right)$ e óxido de zircônia $\left(\mathrm{ZrO}_{2}\right)$, diferem substancialmente das cerâmicas a base de sílica e exigem técnicas adesivas alternativas para a obtenção de uma união forte e duradoura ao material resinoso (BLATZ; SADAN; KERN, 2003).

Portanto, apesar das excelentes propriedades dos materiais com elevado conteúdo cristalino, principalmente a Y-TZP, a dificuldade em se obter valores de união elevados e duradouros entre cimento resinoso e esse tipo de cerâmica acaba limitando o emprego destes materiais. Por isso, é necessário o desenvolvimento de uma técnica confiável que garanta uma união estável a esse material.

Diante disso, este estudo se propôs a avaliar a resistência de união de um agente cimentante à zircônia, frente a diferentes condições da superfície, e também a interação do tratamento superficial com os agentes de união. 


\subsection{Da metodologia}

Os ensaios clínicos controlados são ideais para testar modalidades específicas de tratamento e sua durabilidade em longo prazo. Entretanto, as investigações in vitro são indispensáveis para identificar a qualidade dos materiais antes de sua avaliação clínica (BLATZ; SADAN; KERN, 2003), bem como, permitir a realização de estudos impossíveis de serem realizados diretamente in vivo, como por exemplo, aqueles que versam sobre a resistência de união aos tecidos dentais (RETIEF, 1991). Vale ressaltar que os resultados apresentados em estudos laboratoriais, não implicam, necessariamente, num comportamento clínico similar do material avaliado, uma vez que os estudos in vitro são limitados na reprodução dos fatores que agem in vivo.

A cerâmica empregada neste estudo - Sistema Procera ${ }^{\circledR}$ Allzircon consiste em uma estrutura policristalina tetragonal parcialmente estabilizada com ítrio ( $>99 \% \mathrm{ZrO}_{2}+\mathrm{Y}_{2} \mathrm{O}_{3}+\mathrm{HfO}_{2}$ ), densamente sinterizada pela tecnologia CAD/CAM. Os cilindros de zircônia com $3,5 \mathrm{~mm}$ de diâmetro receberam diferentes tratamentos de superfície, bem como, avaliou-se uma possível interação do tratamento superficial recebido com alguns agentes de união.

Foram avaliados, por meio do uso do cimento resinoso auto-adesivo RelyX $\mathrm{U} 100^{\circledR}$, dois tratamentos superficiais mecânicos, o jateamento com óxido de alumínio $50 \mu \mathrm{m}$ e o jateamento com o sistema Rocatec ${ }^{\circledR}$ e três agentes de união, sendo eles, dois primers metálicos, Metal Zircônia Primer ${ }^{\circledR}$ e Alloy Primer $^{\circledR}$ e um sistema adesivo, Clearfill SE Bond ${ }^{\circledR}$, totalizando 12 grupos experimentais.

Para a realização deste estudo, antes da avaliação de métodos alternativos que pudessem resultar em algum aumento da resistência de união, materiais convencionais foram avaliados durante uma fase piloto (cimento resinoso a base de BisGMA e sistemas adesivos convencionais).

Frente aos diferentes materiais existentes no mercado odontológico, a seleção do cimento resinoso dual auto-adesivo RelyX U100 (3M/ESPE), para o presente estudo, deu-se, fundamentalmente, por ser um material relativamente novo, introduzido no mercado em 2002, por se tratar de um cimento com grande aceitação no mercado odontológico, e por já ser possível encontrar certo número de publicações sobre ele, o que possibilita comparações de 
resultados (PIWOWARCZYK; LAUER; SORENSEN, 2005; ERNST; COHNEN; STENDER; WILLERSHAUSEN, 2005; RADOVIC; MONTICELLI; GORACCI; VULICEVIC FERRARI, 2008).

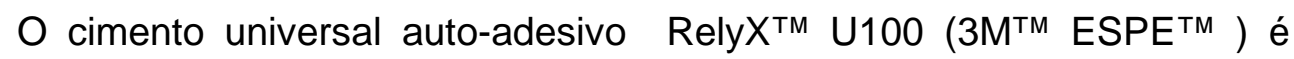
tolerante à umidade. Seu uso está associado a um baixo risco de sensibilidade pós-operatória, além de apresentar uma elevada estabilidade dimensional e liberar flúor (RADOVIC; MONTICELLI; GORACCI; VULICEVIC; FERRARI, 2008). Esse material foi desenvolvido com o objetivo de combinar a facilidade de manipulação e auto-união dos cimentos convencionais com as propriedades mecânicas superiores, a adesividade e as qualidades estéticas de cimentos resinosos. Estas propriedades deveriam resultar em um cimento adequado para garantir a união em metal ou materiais cerâmicos sem comprometer a estabilidade dimensional e em longo prazo. Adicionalmente, buscou-se conseguir resistência adesiva satisfatória, sem a necessidade de aplicar primers ou realizar qualquer outro pré-tratamento (ESPE, 2008).

A natureza ácida dos metacrilatos fosforulados permite a desmineralização da superfície dentária e a penetração do cimento. Uma vez polimerizado, a retenção micromecânica é conseguida entre o cimento e o dente. No entanto, requisitos importantes como elevada resistência mecânica, qualidade estética, e estabilidade dimensional, só podem ser garantidos com o uso de monômeros multifuncionais e melhorados. Essas propriedades são prérequisitos básicos para as situações clínicas que envolvam a cimentação de cerâmicas e restaurações indiretas. Os monômeros do cimento RelyXTM U100 contêm pelo menos dois grupamentos de ácido fosfórico e no mínimo duas ligações duplas de carbono $(C=C)$ por molécula. Isto favorece a formação de ligações cruzadas, que proporcionam, por sua vez, excelentes propriedades mecânicas, além de permitir a união adesiva sem nenhum pré-tratamento (ESPE, 2008).

Para garantir uma resistência adesiva eficiente entre a estrutura dental, o cimento, e a restauração indireta, o cimento deve fornecer uma adesão elevada ao esmalte, à dentina, e à restauração indireta. Na cimentação adesiva convencional, a união é efetiva. Contudo, com o crescente uso das cerâmicas com elevado conteúdo cristalino, à base de alumina e zircônia, concentra-se a atenção sobre o questionamento se o cimento é apropriado para prática clínica 
diária. O material de cimentação deveria ser resistente à hidrólise a fim de criar um selamento marginal durável. Até recentemente, somente os sistemas a base de 4-META, como o Panavia ${ }^{\mathrm{TM}}$, podiam realmente cumprir com esta exigência, apresentando, entretanto, uma sequência operatória complexa. Já o cimento auto-adesivo, além de apresentar elevados valores de união à zircônia, exige uma técnica operatória simples (PIWOWARCZYK \& SORENSEN, 2002; PIWOWARCZYK; LAUER \& SORENSEN, 2005; ESPE, 2008).

Com o objetivo de promover uma rugosidade superficial, os espécimes receberam o jateamento com óxido de alumínio $50 \mu \mathrm{m}$ por 10 segundos e 0 jateamento com o sistema Rocatec, em que o efeito triboquímico do jateamento conduz ao depósito de uma camada molecular de $\mathrm{SiO}_{2}$ na superfície, e em seguida, a superfície é revestida então com o agente silano. Os grupos experimentais foram distribuídos conforme o tratamento recebido (nenhum tratamento; jateamento com $\mathrm{Al}_{2} \mathrm{O}_{3}$; sistema Rocatec) e na sequência, receberam a aplicação de um dos agentes de união (nenhum; sistema adesivo; um dos primers metálicos), totalizando 10 espécimes por grupo.

Os procedimentos com jateamento produzem supostamente microirregularidades na superfície que podem funcionar como iniciadores de trincas e, conseqüentemente, enfraquecer os materiais cerâmicos (BLATZ; SADAN; KERN, 2003; ZHANG; LAWN; REKOW; THOMPSON, 2004b). O estudo feito por Zhang; Lawn; Rekow; Thompson, em 2004b, evidenciou que o jateamento com óxido de alumínio por 5 segundos reduz a resistência da zircônia em cerca de $25 \%$ quando sob carregamento cíclico, devido à geração de microtrincas que resultam em falha precoce do material. Entretanto, os agentes cimentantes capazes de promover uma união durável, podem bloquear essas pequenas falhas criadas na superfície (BLATZ; SADAN; KERN, 2003). O jateamento causa uma transformação da fase monoclínica da zircônia, criando uma camada de esforços compressivos na superfície que neutraliza as falhas induzidas (GUAZZATO; QUACH; ALBAKRY; SWAIN, 2005).

A aplicação de um revestimento triboquímico de sílica que permita união química à resina através de um agente silano tem sido recomendada (KERN \& THOMPSON, 1995; ATSU; KILICARSLAN; KUCUKESMEN; AKA, 2006; OZCAN \& VALLITTU, 2003; ERNST; COHNEN; STENDER; WILLERSHAUSEN, 2005; VALANDRO; DELLA BONA; BOTTINO; NEISSER, 
2005). O sistema Rocatec (3M ESPE) é um método de revestimento de sílica eficaz e de fácil utilização, que inclui 2 etapas de jateamento e a aplicação de um agente silano (ESPE-Sil - 3M ESPE) que irá promover a união da superfície jateada à resina (BLATZ; SADAN; KERN, 2003).

Uma alternativa para melhorar a união a esses materiais de alta resistência é a utilização de agentes de união que contenham 10metacriloiloxidecil di-hidrogênio fosfato (MDP) em sua composição. Por isso, foram incluídos na pesquisa o primer metálico Alloy Primer e o sistema adesivo Clearfill SE Bond, já que os autores Yoshida; Yamashita; Atsuta, em 2004, sugerem que essa combinação é benéfica.

A dificuldade em modificar a superfície das cerâmicas de elevado conteúdo cristalino resultou na busca por técnicas alternativas que sugerem o emprego de materiais que apresentam o monômero MDP em sua composição (WEGNER \& KERN, 2000), porque este monômero se une diretamente aos óxidos presentes na superfície das cerâmicas à base de zircônia e alumina (YOSHIDA; YAMASHITA; ATSUTA, 2004; KERN \& WEGNER, 1998; WEGNER \& KERN, 2000; HUMMEL \& KERN, 2004).

Outro material incluído na pesquisa foi o Metal / Zircônia Primer (Ivoclar), que é um primer mono-componente, desenvolvido para promover união das ligas metálicas ou das cerâmicas a base de óxido de alumínio e óxido de zircônia ao metacrilato dos cimentos resinosos. Como resultado, elevados valores de resistência adesiva são alcançados. Este primer contém um composto de ácido fosfônico como ingrediente ativo, que estabelece uma união química aos óxidos da superfície.

Para a confecção dos espécimes, os cilindros de zircônia, após receber o devido tratamento, eram fixados em um dispositivo metálico, com uma abertura central de $3,5 \mathrm{~mm}$ de diâmetro e $3 \mathrm{~mm}$ de altura, garantindo aos espécimes essa dimensão (ARAUJO \& ASMUSSEN, 1989; MEDINAVALDIVIA, 2007). Na seqüência, os espécimes eram mantidos em umidade absoluta, na água deionizada, por 24 horas em uma estufa a $37^{\circ} \mathrm{C}$, para então serem submetidos ao ensaio mecânico.

Dentre os testes para avaliação da resistência da união dentinacompósito restaurador, o método de cisalhamento apesar de apresentar maior facilidade de realização, comparado aos testes de tração e micro-tração, tem 
como característica uma distribuição não-uniforme de tensões na região de união (DeHOFF; ANUSAVICE; WANG, 1995; DELLA BONA \& VAN NOORT, 1995; PASHLEY; SANO; CIUCCHI; YOSHIYAMA; CARVALHO, 1995).

No teste de cisalhamento, quanto mais distante o ponto de aplicação da tensão em relação à região de união, maior o momento de flexão, resultando não somente em tensões de cisalhamento, mas sim de tração e compressão. As tensões são sensíveis à geometria do carregamento, forma e tamanho do aderente e seu módulo de elasticidade relativo (VAN NOORT; NOROOZI; HOWARD; CARDEW, 1989). De acordo com, DeHoff; Anusavice; Wang, em 1995, o uso de fio ortodôntico ao invés de cinzel é preferível, visto que reduz a concentração de tensões próxima a interface. Além disso, os autores consideram que os testes não avaliam fatores críticos tais como, tempo, distribuição de falhas e instabilidade de trincas.

Estudos prévios avaliaram a resistência adesiva de materiais restauradores adesivos à cerâmica de Y-TZP. Testes de resistência ao cisalhamento e resistência a tração foram os métodos mais utilizados nessas investigações. Em ambos os métodos, os espécimes tiveram apenas uma interface adesiva testada, ou seja, entre a cerâmica e o cimento resinoso. (LUTHY; LOEFFEL; HAMMERLE, 2006; BLATZ; SADAN; MARTIN; LANG, 2004; WOLFART; LEHMANN; WOLFART; KERN, 2007; PIWOWARCZYK; LAUER; SORENSEN, 2005; KERN \& WEGNER, 1998; YOSHIDA; TSUO; ATSUTA, 2006; ATSU; KILICARSLAN; KUCUKESMEN; AKA, 2006; KUMBULOGLU; LASSILA; USER; VALLITTU, 2006).

Da mesma forma, para este trabalho, optou-se pelo teste de cisalhamento com auxilio de uma alça de fio ortodôntico, sob a qual é submetida à força de tração (ARAUJO; ASMUSSEN, 1989; CARDOSO; MELONCINI; PLACIDO; LIMA; TAVARES, 2003; DeHOFF; ANUSAVICE; WANG, 1995; KUMBULOGLU; LASSILA; VALLITTU, 2006; MEDINAVALDIVIA, 2007) para avaliar a resistência de união de um cimento resinoso dual auto-adesivo à zircônia densamente sinterizada sob diferentes condições de superfície.

Os testes de resistência de união auxiliam no desenvolvimento dos sistemas adesivos, técnicas restauradoras e de cimentação. Entretanto, é 
importante saber o que se pode determinar com a utilização de cada um desses testes laboratoriais (SUDSANGIAM \& VAN NOORT, 1999).

\subsection{Dos resultados}

Apesar do domínio da técnica de cimentação para as cerâmicas à base de sílica, o grande aumento do conteúdo cristalino das cerâmicas resultou na eliminação da fase vítrea, o que modificou as características de adesão entre a cerâmica e o cimento resinoso. Considerando que o condicionamento com ácido fluorídrico dissolve a fase vítrea da cerâmica, nas cerâmicas ácidoresistentes (à base de alumina e zircônia), nenhum tipo de ácido produz retenção micromecânica suficiente para o procedimento de união (DERAND \& DERAND, 2000; ÖZCAN \& VALLITTU, 2003). Então, essas estruturas requerem uma técnica alternativa capaz de promover a união ao cimento.

Esse fato corrobora com os achados do presente estudo, já que as superfícies que não receberam nenhum tratamento, seja mecânico ou químico, apresentaram os menores valores de união (3,58 MPa), mostrando que é necessário a realização de algum tratamento superficial nas infra-estruturas de Y-TZP. Então as hipóteses nulas testadas foram rejeitadas, ou seja, os diferentes tratamentos superficiais e os agentes de união influenciam nos valores de resistência adesiva do agente cimentante à estrutura de zircônia.

Dentre as opções de tratamento superficial propostas, optou-se por realizar o jateamento com partículas de óxido de alumínio e jateamento com partículas de sílica, além da aplicação de alguns agentes de união, associando esses métodos.

O jateamento cria uma superfície irregular que favorece a união micromecânica entre a cerâmica e sistema de fixação. O jateamento com óxido de alumínio é o método de tratamento de superfície preferencial para os materiais cerâmicos de alta resistência (BLATZ; SADAN; KERN, 2003; KERN \& THOMPSON, 1994, 1995; WEGNER \& KERN, 2000). Os sistemas micromecânicos de união utilizam essas partículas de abrasão para melhorar a microrretenção e aumentar a área de superfície de união (ÖZCAN; PFEIFFER; NERGIZ, 1998). Esses métodos asperizam a superfície, aumentando sua energia de superfície e, conseqüentemente, o molhamento (BLATZ; SADAN; KERN, 2003). 
Entretanto, alguns autores indicam que as microporosidades criadas pelos tratamentos de superfície podem atuar como os iniciadores de trinca, enfraquecendo os materiais cerâmicos (ZHANG; LAWN; REKOW; THOMPSON, 2004b; KUMBULOGLU; LASSILA; USER; VALLITTU, 2006). Assim, o efeito dessas alterações na durabilidade de restaurações de Y-TZP deve ser investigado em estudos de longo prazo para determinar se a maior retenção conferida às superfícies abrasionadas compensa as mudanças ocorridas nas propriedades mecânicas.

Kern e Thompson, em 1995, relataram que o jateamento com oxido de alumínio promoveu uma união inicial satisfatória com os cimentos convencionais resinosos à base de BisGMA. Todavia, essa união diminui significativamente, abaixo de valores clínicos aceitáveis, após o armazenamento em longo prazo e termociclagem. Isso pode ser explicado pelo fato do jateamento produzir uma aspereza superficial limitada quando comparado as superfícies metálicas. Então a união física e química do cimento resinoso convencional a base de BisGMA à Y-TZP não é resistente ao armazenamento em água, e após um período de imersão, houve a desunião das amostras.

Outra técnica é o revestimento com sílica, em que o efeito triboquímico do jateamento conduz ao depósito de uma camada molecular de $\mathrm{SiO}_{2}$ na superfície. Em seguida a superfície é revestida com o silano para torná-la quimicamente mais reativa à resina (ÖZCAN \& VALLITTU, 2003).

Alguns estudos mostraram que o revestimento triboquímico com sílica pode aumentar a resistência adesiva entre a resina composta e a cerâmica (KERN \& THOMPSON, 1995; WEGNER \& KERN, 2000). Para Kumbuloglu; Lassila; User; Vallittu, em 2006, o sistema Rocatec proporcionou uma união ligeiramente maior que a obtida com o jateamento com partículas de $\mathrm{Al}_{2} \mathrm{O}_{3}$. $\mathrm{O}$ revestimento com sílica pode estimular a superfície, permitindo, assim, a penetração da sílica (KERN \& THOMPSON, 1995). O silano melhora a união entre a sílica aderida na superfície e a matriz resinosa. Uma vantagem deste sistema é que as unidades de jateamento estão disponíveis para uso laboratorial e no consultório (XIBLE; TAVAREZ; ARAUJO; BONACHELA, 2006). O revestimento triboquímico de sílica mostrou um significante aumento da resistência adesiva inicial $(29,2 \mathrm{MPa})$, embora a união não tenha sido 
estável com o tempo e tenha diminuido de maneira significante para 12,8 MPa. O revestimento triboquímico de sílica não produz uma camada uniforme e estável na superfície da zircônia (KERN \& THOMPSON, 1995).

De acordo com os resultados encontrados no presente estudo, os tratamentos de superfície influenciaram de maneira positiva nos valores de resistência adesiva. As superfícies que receberam o jateamento com partículas de sílica (15,33 MPa) apresentaram os melhores valores quando comparadas as superfícies jateadas com óxido de alumínio (11,93 MPa) e as superfícies que não receberam nenhum tratamento $(6,56 \mathrm{MPa})$, mostrando uma diferença estatisticamente significante entre eles. Para a realização dessa comparação, os diferentes agentes de união utilizados no estudo, foram desconsiderados, ou seja, foi feita uma média de todos os espécimes que receberam os tratamentos superficiais mecânicos, independente da aplicação ou não dos agentes de união.

Quando a comparação é feita apenas entre os grupos Co, CoJat e CoRoc, em que não houve a associação dos tratamentos superficiais com os agentes de união, verifica-se que não houve uma diferença estatística significante entre o grupo sem tratamento e o grupo que recebeu jateamento com óxido de alumínio. Nesse caso, fica claro que o jateamento é mais eficiente quando associado com algum agente de união.

Dentre as alternativas possíveis para se criar uma interação química entre zircônia e agente cimentante está o emprego de materiais que contenham monômeros fosfatados na composição. Por isso, neste estudo buscou-se associar o cimento resinoso auto-adesivo a base de monômero éster fosfato, com agentes de união de formulação semelhante.

Atsu; Kilicarslan; Kucukesmen; Aka, em 2006, verificaram diferentes condições de superfície e concluíram que a resistência adesiva foi significativamente superior no grupo que recebeu o revestimento triboquímico de sílica, associado com a aplicação de um agente de união (Clearfil Liner Bond 2V Primer; Kuraray) e um silano (Clearfil Porcelain Bond Activator; Kuraray), que foram misturados e preparados conforme as recomendações do fabricante. Além disso, verificou que a resistência adesiva foi significantemente diferente para os grupos tratados com sílica, quando comparados aos grupos 
jateados com óxido de alumínio, o que indica que esse sistema melhora a união a zircônia.

Ao contrário do encontrado neste trabalho, dentre os materiais avaliados, foi a associação do jateamento com óxido de alumínio com o sistema adesivo Clearfill SE Bond, à base de MDP, que apresentou os maiores valores de resistência adesiva (20,58 MPa), embora essa diferença não tenha sido significante quando comparada ao revestimento com sílica (17,79 MPa). Em contrapartida, para os primers metálicos, Alloy Primer e Metal/Zircônia Primer, o revestimento com sílica (Rocatec) mostrou maiores valores $(14,47$ $\mathrm{MPa}$ e 17,30 MPa, respectivamente), ainda que essa diferença tenha sido significante apenas para o Metal/Zircônia Primer.

Corroborando com os resultados encontrados, de acordo com Yoshida; Yamashita; Atsuta, em 2004, a aplicação prévia de um primer contendo MDP pode fazer com que o emprego de um cimento contendo o mesmo monômero não seja necessário ou poderia, até mesmo, melhorar essa união.

Diante dos resultados encontrados, mesmo que os agentes de união tenham se comportado de maneira diferente frente aos tratamentos de superfície, pode-se verificar que, comparando-se aos grupos que não receberam a aplicação de nenhum agente de união, CoJat (5,93 MPa) e CoRoc $(11,85 \mathrm{MPa})$, a associação de um tratamento superficial com um agente de união é valida.

$\mathrm{Na}$ comparação entre os diferentes agentes de união, o sistema adesivo Clearfill SE Bond (17,07 MPa) mostrou um comportamento estatisticamente superior aos demais materiais, talvez por se tratar de um material que contém um primer e um adesivo, ambos com MDP na composição, já que os outros agentes de união são apenas primers. Entre os primers, o Metal/Zircônia Primer $(11,26 \mathrm{MPa})$ teve um melhor desempenho que o Alloy Primer $(10,01$ $\mathrm{MPa}$ ), mas sem diferença estatística.

Tendo em vista que as técnicas de cimentação para as cerâmicas a base de Y-TZP ainda não estão bem estabelecidas, pesquisas futuras são necessárias para confirmar os dados encontrados e até mesmo investigar o comportamento desses materiais em longo prazo, mas as informações obtidas podem ser consideradas importantes para a compreensão das características e do comportamento dos materiais avaliados. 


\section{CONCLUSÕES}




\section{CONCLUSÕES}

Com base nos resultados obtidos, após análise estatística e discussão dos mesmos, pode-se concluir que:

1. a realização de um tratamento de superfície aumentou os valores de resistência de união entre a cerâmica a base de zircônia e o cimento autoadesivo. Dentre os tratamentos realizados, o jateamento com o sistema Rocatec, apresentou valores significantemente maiores que o jateamento com óxido de alumínio;

2. a aplicação dos agentes de união resultou em uma maior resistência adesiva. Entre os primers, o Metal Zircônia Primer apresentou maior valor de resistência de união que o Alloy Primer;

3. a aplicação do sistema adesivo Clearfill SE Bond teve um desempenho estatisticamente superior aos demais materiais;

4. a associação de um tratamento superficial com um agente de união é válida, pois promoveu os maiores valores de resistência adesiva. 


\section{REFERÊNCIAS}

\section{BIBLIOGRÁFICAS}

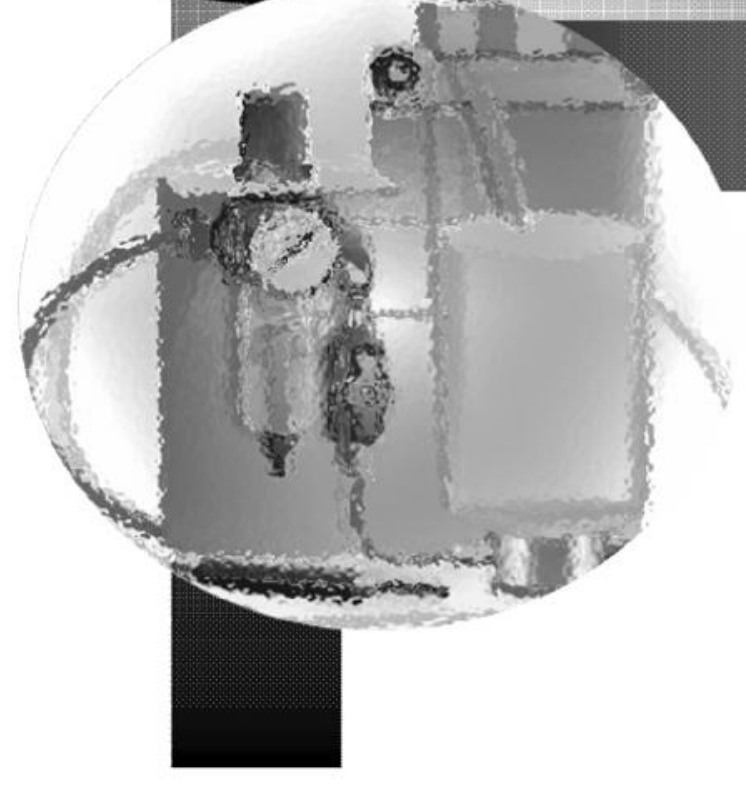




\section{REFERÊNCIAS}

Al-Salehi SK, Burke FJ. Methods used in dentin bonding tests: an analysis of 50 investigations on bond strength. Quintessence Int. 1997 Nov;28(11):71723.

Anusavice KJ. Cerâmicas odontológicas. In: Anusavice,KJ.Phillip's: materiais

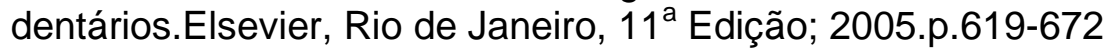

Araujo PA, Asmussen E. Bonding to dentine with a simplified Gluma system. Int Dent J. 1989;39(4):253-7.

Atsu SS, Kilicarslan MA, Kucukesmen HC, Aka PS. Effect of zirconium-oxide ceramic surface treatments on the bond strength to adhesive resin. J Prosthet Dent 2006; 95(6): 430-6.

Blatz MB, Sadan A, Kern M. Resin-ceramic bonding: a review of the literature. J Prosthet Dent 2003; 89(3): 268-74.

Blatz MB, Sadan A, Martin J, Lang B. In vitro evaluation of shear bond strengths of resin to densely-sintered high-purity zirconium-oxide ceramic after long-term storage and thermal cycling. J Prosthet Dent 2004;91(4):356-62.

Bottino, MA; Quintas A F, Miyashita E, Giannini V. Estética em reabilitação oral metal-free. São Paulo: Artes Médicas, 2001.

Bowen RL. Properties of a silica-reinforced polymer for dental restorations. J Am Dent Assoc 1963;66:57-64.

Buonocore MG. A simple method of increasing the adhesion of acrylic filling materials to enamel surfaces. J Dent Res. 1955 Dec; 34(6): 849-53.

Cobb DS, Vargas MA, Fridrich TA, Bouschlicher MR. Metal surface treatment: characterization and effect on composite-to-metal bond strength. Oper Dent $2000 ; 25(5): 427-33$.

Cardoso PE, Meloncini MA, Placido E, Lima Jde O, Tavares AU. Influence of the substrate and load application method on the shear bond strength of two adhesive systems. Oper Dent 2003;28(4):388-94. 
Chevalier J, Olagnon C, Fantozzi G: Crack propagation and fatigue in zirconiabased composites. Composites: Part A. 1999; 30: 525-530.

Chevalier J. What future for zirconia as a biomaterial? Biomaterials 2006; 27:535-43.

Chevalier J, Deville S, Münch E, Jullian R, Lair F. Critical effect of cubic phase on aging in $3 \mathrm{~mol} \%$ yttria-stabilized zirconia ceramics for hip replacement prosthesis. Biomaterials 2004; 25(24):5539-5545.

Craig RG, Powers JM. Materiais Dentários Restauradores. In: Cerâmicas. São Paulo: Livraria Santos; 11ª Edição; 2004. p. 551- 574.

DeAza AH, Chevalier J, Fantozzi G, Schehl M, Torrecillas R. Crack growth resistance of alumina, zirconia and zirconia toughened alumina ceramics for joint prostheses. Biomaterials. 2002;23(3):937-45.

Della Bona A, van Noort R. Shear vs. tensile bond strength of resin composite bonded to ceramic. J Dent Res 1995; 74(9):1591-6.

Della Bona A, Shen C, Anusavice KJ.Work of adhesion of resin on treated lithia disilicate-based ceramic.Dent Mater 2004; 20(4):338-44.

Dunn WJ, Soderholm KJ. Comparison of shear and flexural bond strength tests versus failure modes of dentin bonding systems. Am J Dent 2001;14(5):297-303.

Derand $\mathrm{P}$, Derand $\mathrm{T}$. Bond strength of luting cements to zirconium oxide ceramics. Int J Prosthodont 2000; 13(2): 131-5.

Derand T, Molin M, Kvam K. Bond strength of composite luting cement to zirconia ceramic surfaces. Dent Mater. 2005; 21(12):1158-62.

DeHoff $\mathrm{PH}$, Anusavice KJ, Wang Z. Three-dimensional finite element analysis of the shear bond test. Dent Mater 1995; 11(2):126-31.

Ernst CP, Cohnen U, Stender E, Willershausen B. In vitro retentive strength of zirconium oxide ceramic crowns using different luting agents. J Prosthet Dent 2005; 93(6): 551-8. 
Espe 3M. Rely X Unicem self-adhesive universal resin cement. Germany: 3M ESPE; 2008 (Bula).

Francischone CE, Vasconcelos LW. Restaurações estéticas sem metal: Conceito Procera. São Paulo: Quintessence Editora, 2002.

Fusayama T, Nakamura M, Kurosaki N, Iwaku M. Non-pressure adhesion of a new adhesive restorative resin. J Dent Res 1979; 58(4):1364-70.

Garcia FCP, D’Alpino PHP, Terada RSS, Carvalho RM. Testes mecânicos para a avaliação laboratorial da união resina/dentina. Rev Fac Odontol Bauru 2002; 10(3): 118-27.

Garvie RC, Hannink RH, Pascoe RT. Ceramic steel? Nature 1975;258:703-4.

Gomes EA, Assunção WG, Rocha EP, Santos PH. Cerâmicas odontológicas: o estado atual. Cerâmica 2008; 54:319-325.

Guazzato M, Albakry M, Ringer SP, Swain MV. Strength, fracture toughness and microstructure of a selection of all-ceramic materials. Part II. Zirconiabased dental ceramics. Dent Mater 2004; 20(5):449-56.

Guazzato M, Albakry M, Ringer SP, Swain MV. Strength, fracture toughness and microstructure of a selection of all-ceramic materials. Part I. Pressable and alumina glass-infiltrated ceramics.Dent Mater 2004b; 20(5):441-8.

Guazzato M, Quach L, Albakry M, Swain MV. Influence of surface and heat treatments on the flexural strength of Y-TZP dental ceramic. J Dent 2005; 33(1):9-18.

Hannink RHJ, Kelly PM, Muddle BC. Transformation toughening in zirconiacontaining ceramics. J Am Ceram Soc 2000; 83(3):461-87.

Hench LL. Bioceramics. J Am Ceram Soc 1998; 81 (7): 1705-1728

Höland W, Schweiger M, Frank M, Rheinberger V. A comparison of the microstructure and properties of the IPS Empress 2 and the IPS Empress glass-ceramics. J Biomed Mater Res 2000; 53:297-303.

Hummel M, Kern M. Durability of the resin bond strength to the alumina ceramic Procera. Dent Mater 2004; 20(5):498-508. 
Kosmac T, Oblak C, Jevnikar P, Funduk N, Marion L. The effect of surface grinding and sandblasting on flexural strength and reliability of Y-TZP zirconia ceramic. Dent Mater 1999; 15(6):426-33.

Kern M, Wegner SM. Bonding to zirconia ceramic: adhesion methods and their durability. Dent Mater 1998; 14(1):64-71.

Kern M, Thompson VP. Bonding to glass infiltrated alumina ceramic: adhesive methods and their durability. J Prosthet Dent 1995; 73(3): 240-9.

Kumbuloglu O, Lassila LV, User A, Vallittu PK. Bonding of resin composite luting cements to zirconium oxide by two air-particle abrasion methods. Oper Dent 2006; 31(2):248-55.

Kelly JR, Nishimura I, Campbell SD. Ceramics in dentistry: historical roots and current perspectives. J Prosthet Dent 1996; 75(1):18-32.

Luthy $\mathrm{H}$, Loeffel $\mathrm{O}$, Hammerle $\mathrm{CH}$. Effect of thermocycling on bond strength of luting cements to zirconia ceramic. Dent Mater 2006; 22(2):195-200.

Luthardt RG, Holzhuter M, Sandkuhl O, Herold V, Schnapp JD, Kuhlisch E, et al. Reliability and properties of ground Y-TZP-zirconia ceramics. J Dent Res 2002; 81(7): 487-91.

McLean JW. The science and art of dental ceramics. Oper Dent 1999; 16(4):149-56.

McLean JW. Evolution of dental ceramics in the twentieth century. J Prosthet Dent 2001; 85(1):61-6.

McLean JW, Hughs TH. The reinforcement of dental porcelain with ceramic oxides. Br Dent J 1965; 119(6):251-67.

Medina-Valdivia JR. Resistência de união de um cimento resinosoa diferentes superfícies de alumina densamente sinterizada [dissertação]. Bauru (SP): Faculdade de Odontologia de Bauru, Universidade de São Paulo; 2007.

Nakabayashi N, Kojima K, Masuhara E. The promotion of adhesion by the infiltration of monomers into tooth substrates. J Biomed Mater Res A 1982;16(3):265-73. 
Nobel Biocare. Nobel rondo zirconia. Suécia; 2005 (Manual). www.nobelbiocare.com .Acesso em março de 2008.

Odén A, Andersson M, Krystek-Ondracek I, Magnusson D. Five-year clinical evaluation of Procera AllCeram crowns. J Prosthet Dent 1998; 80(4):450-6.

Øilo G, Austrheim EK. In vitro quality testing of dentin adhesives. Acta Odontol Scand 1993; 51(4):263-9.

Ozcan M, Vallittu PK. Effect of surface conditioning methods on the bond strength of luting cement to ceramics. Dent Mater 2003; 19(8):725-31.

Ozcan M. The use of chairside silica coating for different dental applications: a clinical report. J Prosthet Dent 2002; 87(5): 469-72.

Özcan M, Pfeiffer P, Nergiz I. A brief history and current status of metal-and ceramic surface-conditioning concepts for resin bonding in dentistry Quintessence Int. 1998; 29(11): 713-724.

Pallis K, Griggs JA, Woody RD, Guillen GE, Miller AW. Fracture resistance of three all-ceramic restorative systems for posterior applications. J Prosthet Dent 2004; 91(6):561-9.

Pashley DH, Sano H, Ciucchi B, Yoshiyama M, Carvalho RM. Adhesion testing of dentin bonding agents: a review. Dent Mater 1995; 11(2):117-25.

Piconi C, Maccauro G. Zirconia as a ceramic biomaterial. Biomaterials. 1999; 20(1):1-25.

Piwowarczyk A, Lauer HC, Sorensen JA. In vitro shear bond strength of cementing agents to fixed prosthodontic restorative materials. J Prosthet Dent 2004; 92(3):265-73.

Piwowarczyk A, Lauer HC, Sorensen JA. The shear bond strength between luting cements and zirconia ceramics after two pre-treatments. Oper Dent 2005; 30(3):382-8.

Piwowarczyk A, Berge HX, Lauer HC, Sorensen JA. Shear Bond Strength of Cements at Zirconia and Lithium Disilicate Ceramics. J Dent Res 2002; 81 (Spec Iss A): 401. 
Radovic I, Monticelli F, Goracci C, Vulicevic ZR, Ferrari M. Self-adhesive resin cements: a literature review. J Adhes Dent. 2008; 10(4):251-8.

Retief DH. Standardizing laboratory adhesion tests. Am J Dent 1991; $4(5): 231-6$.

Sadan A, Blatz MB, Lang B. Clinical considerations for densely sintered alumina and zirconia restorations: part 2. Int J Periodontics Restorative Dent 2005; 25(4): 343-9.

Silikas N, Wincott PL, Vaughan D, Watts DC, Eliades G. Surface characterization of precious alloys treated with thione metal primers. Dent Mater 2007; 23(6): 665-73.

Sinhoreti MA, Consani S, De Goes MF, Sobrinho LC, Knowles JC. Influence of loading types on the shear strength of the dentin-resin interface bonding. $J$ Mater Sci Mater Med 2001; 12(1):39-44.

Sudsangiam S, van Noort R. Do dentin bond strength tests serve a useful purpose? J Adhes Dent 1999; 1(1): 57-67.

Suárez MJ, Lozano JF, Paz Salido M, Martínez F. Three-year clinical evaluation of In-Ceram Zirconia posterior FPDs. Int J Prosthodont 2004; 17(1):35-8.

Soares CJ, Soares PV, Pereira JC, Fonseca RB. Surface treatment protocols in the cementation process of ceramic and laboratory-processed composite restorations: a literature review. J Esthet Restor Dent 2005; 17(4):224-35.

Tinschert J, Natt G, Mautsch W, Spiekermann H, Anusavice KJ. Marginal fit of alumina-and zirconia-based fixed partial dentures produced by a CAD/CAM system. Oper Dent 2001; 26(4): 367-74.

Valandro LF, Della Bona A, Antonio Bottino M, Neisser MP. The effect of ceramic surface treatment on bonding to densely sintered alumina ceramic. $J$ Prosthet Dent 2005; 93(3): 253-9.

Van Noort R, Noroozi S, Howard IC, Cardew G. A critique of bond strength measurements. J Dent. 1989;17(2):61-7.

Van Noort R. Introdução aos Materiais Dentários. In: Cerâmicas dentais. Porto Alegre: Artmed, 2ª edição, 2004: 269-287. 
Xible AA, Tavarez RRJ, Araujo CRP, Bonachela WC. Effect of silica coating and silanization on flexural and composite-resin bond strengths of zirconia posts: An in vitro study. Prosthet Dent 2006; 95:224-9.

Zhang Y, Lawn BR, Rekow ED, Thompson VP. Effect of sandblasting on the long-term performance of dental ceramics. J Biomed Mater Res B Appl Biomater 2004a; 71(2):381-6.

Zhang Y, Pajares A, Lawn BR. Fatigue and damage tolerance of Y-TZP ceramics in layered biomechanical systems. J Biomed Mater Res B Appl Biomater 2004b; 71(1): 166-71.

Wagner WC, Chu TM. Biaxial flexural strength and indentation fracture toughness of three new dental core ceramics. J Prosthet Dent 1996;76(2):140-4.

Wolfart M, Lehmann F, Wolfart S, Kern M. Durability of the resin bond strength to zirconia ceramic after using different surface conditioning methods. Dent Mater 2007; 23(1):45-50.

Wegner SM, Kern M. Long-term resin bond strength to zirconia ceramic. J Adhes Dent 2000; 2(2):139-47.

Yoshida K, Yamashita M, Atsuta M. Zirconate coupling agent for bonding resin luting cement to pure zirconium. Am J Dent 2004; 17: 249-52.

Yoshida K, Kamada K, Atsuta M. Effects of two silane coupling agents, a bonding agent, and thermal cycling on the bond strength of a CAD/CAM composite material cemented with two resin luting agents. J Prosthet Dent 2001; 85:184-9.

Yoshida K, Taira Y, Sawase T, Atsuta M. Effects of adhesive primers on bond strength of self-curing resin to cobalt-chromium alloy. J Prosthet Dent 1997; 77(6):617-620.

Yoshida K, Tsuo Y and Atsuta M. Bonding of dual-cured resin cement to zirconia ceramic using phosphate acid ester monomer and zirconate coupler. J Biomed Mater Res B Appl Biomater 2006; 77B:28-33. 


\section{ANEXOS}




\section{ANEXOS}

ANEXO A: Valores da resistência de união dos grupos experimentais controle.

\begin{tabular}{|c|c|c|}
\hline Controle (U100) & Resistência de união (kgf) & Resistência de união (MPa) \\
\hline Co & 4,6 & 4,7 \\
\hline Co & 4,1 & 4,2 \\
\hline Co & 2,5 & 2,6 \\
\hline Co & 2,9 & 3,0 \\
\hline Co & 2,7 & 2,8 \\
\hline Co & 4,3 & 4,4 \\
\hline Co & 2,3 & 2,4 \\
\hline Co & 5,7 & 5,8 \\
\hline Co & 3,3 & 3,4 \\
\hline Co & 2,7 & 2,8 \\
\hline CoJat & 6,6 & 6,7 \\
\hline CoJat & 3,3 & 3,4 \\
\hline CoJat & 5,0 & 5,1 \\
\hline CoJat & 5,5 & 5,6 \\
\hline CoJat & 6,0 & 6,1 \\
\hline CoJat & 5,1 & 5,2 \\
\hline CoJat & 4,9 & 5,0 \\
\hline CoJat & 6,0 & 6,1 \\
\hline CoJat & 9,7 & 9,9 \\
\hline CoJat & 6,0 & 6,1 \\
\hline CoRoc & 8,8 & 9,0 \\
\hline CoRoc & 9,4 & 9,6 \\
\hline CoRoc & 13,3 & 13,6 \\
\hline CoRoc & 10,1 & 10,3 \\
\hline CoRoc & 8,3 & 8,5 \\
\hline CoRoc & 10,1 & 10,3 \\
\hline CoRoc & 15,6 & 15,9 \\
\hline CoRoc & 6,7 & 6,8 \\
\hline CoRoc & 13,4 & 13,7 \\
\hline CoRoc & 9,4 & 9,6 \\
\hline
\end{tabular}


ANEXO B: Valores da resistência de união dos grupos que utilizaram o primer Alloy Primer.

\begin{tabular}{ccc}
\hline Alloy Primer & Resistência de união (kgf) & Resistência de união (MPa) \\
\hline Ap & 5,7 & 5,8 \\
Ap & 3,3 & 3,4 \\
Ap & 4,1 & 4,2 \\
Ap & 4,0 & 4,1 \\
Ap & 4,2 & 4,3 \\
Ap & 5,2 & 5,3 \\
Ap & 5,5 & 5,6 \\
Ap & 3,4 & 3,5 \\
Ap & 3,3 & 3,4 \\
Ap & 10,0 & 10,2 \\
ApJat & 9,3 & 9,5 \\
ApJat & 8,4 & 8,6 \\
ApJat & 7,5 & 7,7 \\
ApJat & 9,1 & 9,3 \\
ApJat & 13,0 & 13,3 \\
ApJat & 8,0 & 8,2 \\
ApJat & 12,7 & 13,0 \\
ApJat & 13,7 & 14,0 \\
ApJat & 8,7 & 8,9 \\
ApJat & 10,3 & 10,5 \\
ApRoc & 11,6 & 11,8 \\
ApRoc & 10,3 & 10,5 \\
ApRoc & 10,8 & 11,0 \\
ApRoc & 29,9 & 30,5 \\
ApRoc & 12,4 & 12,7 \\
ApRoc & 14,4 & 14,7 \\
ApRoc & 10,6 & 10,8 \\
ApRoc & 16,8 & 17,1 \\
ApRoc & 10,4 & 10,6 \\
ApRoc & 17,5 & 17,9 \\
\hline & & \\
\hline
\end{tabular}


ANEXO C: Valores da resistência de união dos grupos que utilizaram o sistema adesivo Clearfill SE Bond.

\begin{tabular}{ccc}
\hline Clearfill SE Bond & Resistência de união (kgf) & Resistência de união (MPa) \\
\hline $\mathrm{Cb}$ & 12,4 & 12,7 \\
$\mathrm{Cb}$ & 12,5 & 12,8 \\
$\mathrm{Cb}$ & 10,9 & 11,1 \\
$\mathrm{Cb}$ & 16,4 & 16,7 \\
$\mathrm{Cb}$ & 16,0 & 16,3 \\
$\mathrm{Cb}$ & 8,2 & 8,4 \\
$\mathrm{Cb}$ & 8,5 & 8,7 \\
$\mathrm{Cb}$ & 13,7 & 14,0 \\
$\mathrm{Cb}$ & 9,3 & 9,5 \\
$\mathrm{Cb}$ & 10,1 & 10,3 \\
CbJat & 26,2 & 26,7 \\
CbJat & 26,9 & 27,5 \\
CbJat & 23,3 & 23,8 \\
CbJat & 23,9 & 24,4 \\
CbJat & 19,1 & 19,5 \\
CbJat & 17,9 & 18,3 \\
CbJat & 15,7 & 16,0 \\
CbJat & 21,3 & 21,7 \\
CbJat & 12,5 & 12,8 \\
CbJat & 19,0 & 19,4 \\
CbRoc & 23,8 & 24,3 \\
CbRoc & 12,4 & 12,7 \\
CbRoc & 24,7 & 25,2 \\
CbRoc & 13,9 & 14,2 \\
CbRoc & 21,5 & 22,0 \\
CbRoc & 13,5 & 13,8 \\
CbRoc & 18,1 & 18,5 \\
CbRoc & 22,8 & 23,3 \\
CbRoc & 10,1 & 10,3 \\
CbRoc & 17,1 & 17,5 \\
\hline
\end{tabular}


ANEXO D: Valores da resistência de união dos grupos que utilizaram o primer Metal Zircônia Primer.

\begin{tabular}{|c|c|c|}
\hline $\begin{array}{c}\text { Metal Zircônia } \\
\text { Primer } \\
\end{array}$ & Resistência de união (kgf) & Resistência de união (MPa) \\
\hline Mzp & 7,5 & 7,7 \\
\hline Mzp & 5,2 & 5,3 \\
\hline Mzp & 5,6 & 5,7 \\
\hline Mzp & 2,5 & 2,6 \\
\hline Mzp & 5,7 & 5,8 \\
\hline Mzp & 4,1 & 4,2 \\
\hline Mzp & 2,5 & 2,6 \\
\hline Mzp & 7,3 & 7,5 \\
\hline Mzp & 10,1 & 10,3 \\
\hline Mzp & 4,6 & 4,7 \\
\hline MzpJat & 13,0 & 13,3 \\
\hline MzpJat & 11,8 & 12,1 \\
\hline MzpJat & 10,1 & 10,3 \\
\hline MzpJat & 11,4 & 11,6 \\
\hline MzpJat & 9,8 & 10,0 \\
\hline MzpJat & 6,3 & 6,4 \\
\hline MzpJat & 9,7 & 10,0 \\
\hline MzpJat & 9,0 & 9,2 \\
\hline MzpJat & 11,1 & 11,3 \\
\hline MzpJat & 10,6 & 10,8 \\
\hline MzpRoc & 9,3 & 9,5 \\
\hline MzpRoc & 19,2 & 19,6 \\
\hline MzpRoc & 19,3 & 19,7 \\
\hline MzpRoc & 13,2 & 13,5 \\
\hline MzpRoc & 18,1 & 18,5 \\
\hline MzpRoc & 17,4 & 17,8 \\
\hline MzpRoc & 21,8 & 22,2 \\
\hline MzpRoc & 15,1 & 15,4 \\
\hline MzpRoc & 14,6 & 14,9 \\
\hline MzpRoc & 25,0 & 25,5 \\
\hline
\end{tabular}

